\title{
ARQUIVOS DE MEURO-PSIQUIATRIM
}

Volume $29 \cdot$ N.:.3

Setembro, de 1971

\section{AFECÇõES NEUROLÓGICAS DA INFÂNCIA DETERMINADAS POR FATORES METABÓLICOS}

\author{
Jorge ARMBrust-FigueIREdo *
}

O número de moléstias devidas a êrros inatos do metabolismo vem sendo aumentado progressivamente pela identificação de novas síndromes e esclarecimento da natureza bioquímica dos bloqueios metabólicos responsáveis. Por outro lado, a introdução de novos meios diagnósticos tem permitido que algumas dessas moléstias, inicialmente consideradas como devidas a defeitos enzimáticos únicos e apresentando sintomatologia extremamente variada, sejam subdivididas em diferentes entidades, cada uma com sua própria alteração metabólica ou enzimática.

Várias enzimopatias podem, hoje, ser reconhecidas em idade precoce; pesquisas em larga escala vem sendo desenvolvidas para o reconhecimento de substâncias anormais no sangue e na urina. O emprêgo de análises enzimáticas em leucócitos e hemácias vem sendo difundido tornando maiores as possibilidades de diagnóstico. Em muitas doenças, particularmente aquelas acompanhadas por deficiência mental, existe premência no diagnóstico definitivo, pois em muitas instâncias o tratamento precoce melhora o prognóstico.

Uma revisão das moléstias devidas a êrros do metabolismo é tarefa difícil devido ao constante trabalho desenvolvido nos principais centros de pesquisas, aumentando diàriamente os conhecimentos sôbre essas entidades. $O$ melhor conhecimento dos mecanismos genéticos e dos mecanismos metabólicos faz pressupor que, em futuro próximo, muitas das idéias hoje admitidas sejam ultrapassadas e novas formas clínicas ou novas entidades sejam descritas.

Resumo de relatório apresentado ao IV Congresso Brasileiro de Neurologia (Pôrto Alegre, 5 a 9 de julho de 1970).

* Professor de Neurologia na Faculdade de Medicina de Ribeirão Prêto, Universidade de São Paulo. 
1. DISTURBIOS DO METABOLISMO DOS AMINOACIDOS

1.1. Fenilcetonúria

1.2. Moléstia de Hartnup

1.3. Moléstia da urina com odôr de xarope de bôrdo

1.4. Sindrome de Lowe

1.5. Moléstia de Lesch-Nyhan

2. DISTURBIOS DO METABOLISMO DOS LIPIDES

2.1. Moléstia de Gaucher

2.2. Idiotias amauróticas:

2.2.1. forma infantil (Tay-Sachs)

2.2.2. forma infantil tardia (Bielschowsky)

2.2.3. forma juvenil (Spielmeyer-Vogt)

2.2.4. forma tardia (Kufs)

2.2.5. forma congênita (Norman-Wood)

2.3. Moléstia de Niemann-Pick

2.4. Leucodistrofias :

2.4.1. Moléstia de Krabbe

2.4.2. Moléstia de Pelizaeus-Merzbacher

2.4.3. Leucodistrofia metacromática (doença de Scholi?

2.5. Moléstia de Refsum

2.6. Moléstia de Wolman

2.7. Sindrome de Bassen-Kornzweig

3. DISTÓRBIOS DO METABOLISMO DOS HIDRATOS DE CARBONO

3.1. Galactosemia

3.2. Glicogenoses :

3.2.1. Moléstia de Pompe

3.2.2. Moléstia de McArdle

3.2.3. Moléstia de Tarui

3.2.4. Moléstia de Thomson

3.3. Intolerância à frutose

3.4. Mucopolissacaridoses:

3.4.1. Moléstia de Hurler (gargulismo)

3.4.2. Moléstia de Hunter

3.4.3. Moléstia de Sanfilippo

3.4.4. Moléstia de Mórquio

3.4.5. Moléstia de Scheie

3.4.6. Moléstia de Maroteaux e Lamy

4. DISTURBIOS DO METABOLISMO DAS METAL-PROTEINAS

4.1. Degeneração hepatolenticular 


\section{DISTURBIOS DO METABOLISMO DOS AMINOACIDOS}

\section{Fenilcetonúria (oligofrenia fenilpirúvica).}

Trata-se de doença de caráter genético, transmitida de modo recessivo, caracterizada por deficiência mental e excreção urinária anormal de fenilalanina e seus metabolitos. A doença foi reconhecida pela primeira vez em 1934, por Fölling. No Brasil, o primeiro caso foi descrito por FerreiraFernandes ${ }^{20}$ em 1950; ulteriormente, Nóbrega e col. ${ }^{32}$, Esperon ${ }^{19}$ e Diament e Lefèvre ${ }^{17}$ fizeram publicações a respeito. Extensivos estudos clínicos e pesquisas químicas na urina, sangue, líquido cefalorraqueano e cérebro têm sido publicadas.

A incidência da moléstia em gıandes populações não é ainda conhecida, sendo calculada em 1:10.000 nos Estados Unidos. Sua freqüência entre crianças retardadas e internadas é de $1 \%$ no nordeste dos Estados Unidos ${ }^{7}$, de $1,2 \%$ na Inglaterra ${ }^{33}$ e de $0,04 \%$ na Suiça ${ }^{10}$. Nóbrega e col. ${ }^{32}$ encontraram $1,6 \%$ entre 309 crianças estudadas.

O defeito bioquímico primário é a ausência de fenlialanina hidroxilase, enzima hepático que transforma a fenilalanina em tirosina. Quando a tirosina não pode ser formada, a fenilalanina é acumulada no organismo. Desde que a fenilalanina também é metabolisada por vias acessórias, existe formação de ácido fenilpirúvico, ácido fenil-lático, ácido fenil-acético e de fenil acetilglutamina, metabolitos que são excretados pela urina, juntamente com a fenllalanina. Outra reação permite a transformação de cêrca de $10 \%$ do excesso de fenilalanina em ácido orto-hidroxifenil acético, que pode ser encontrado na urina de pacientes com fenilcetonúria, mesmo quando o nivel de fenilalanina no plasma é inferior a $15 \mathrm{mg}$ por $100 \mathrm{ml}$.

Há evidências de que êstes produtos que se acumulam no organismo produzem alteraçōes secundárias no metabolismo da tirosina e do triptofano. Assim, o excesso de fenilalanina inibe a tirosinase, enzima responsável pela transformação da tirosina em melanina. De modo semelhante, o aumento da excreção de ácido indol-pirúvico e de ácido indol-acético, bem como a queda de 5-hidroxitriptamina (serotonina) no sangue são explicados pela inibição das enzimas que metabolisam o triptofano.

As alterações patológicas permaneceram imprecisas durante vários anos. Em 1950, Alvord e col. ${ }^{1}$ chamaram a atenção para as alteraçōes da mlelina; áreas de desmielinização no cérebro, acompanhadas de astrogliose e escassos sinais de substânclas sudanofílicas. Em 1952, Benda ' já assinalara intensa desmielinização da substância branca do encéfalo, cerebelo e medula. Trabalhos subsequientes ${ }^{12},{ }^{24}$ confirmaram as alterações da mielina e Scholz $^{35}$ e Poser e van Bogaert ${ }^{34}$ interpretaram os achados como sugestivos de leucodistrofia ou distúrbio do anabolismo da mielina. Crome e Pare ${ }^{14}$ e Bechar e col. 5 observaram extensa e intensa desmielinização da substância branca cerebral, acompanhada de intensa gliose, aparecimento de produtos sudanofilicos e áreas de grande vacuolização. Mais recentemente, Malamud ${ }^{20}$ concluiu que existem alteraçōes de mielina em todos os casos de fenilcetonúria, em intensidade que depende da idade do paciente e do tempo de duração da moléstia.

Em geral as crianças afetadas pela doença têm pele muito clara, cabelos louros e olhos azuis. Freqüentemente apresentam tendência para pele oleosa, seborrêica, com alterações eczematosas e odor de môfo ou bolor. A criança parece normal ao nascimento e assim permanece durante o periodo neonatal. Os níveis de fenilalanina no plasma são normais ao nascer e o 
ácido fenilpirúvico não está presente na urina, até que a taxa de fenilalanina aumente no plasma até $15 \mathrm{mg}$ por $100 \mathrm{ml}$. Esta elevação pode existir já no sexto dia de vida, mas geralmente ocorre mais tardiamente, no máximo até os 35 dias. Nesta fase se inicia a lesão cerebral, que alcança sua maior intensidade ao redor dos 2 ou 3 anos de idade. O nível intelectual, em cêrca de $80 \%$ das crianças não tratadas, é extremamente baixo. Crises epilépticas ocorrem em cêrca de um terço dos pacientes, sendo tanto mais frequentes quanto maior o tempo de duração da modéstia. Os tipos clínicos dessas crises são os mais variados, podendo surgir manifestações focais ou generalizadas. Do ponto de vista eletrencefalográfico, a maioria dos pacientes apresenta algum tipo de anormalidade elétrica cerebral, tendo sido observadas hipsarritmias, descargas focais ou múltiplas por espículas ou poliespículas, disritmia difusa e generalizada, lentificação de base com atividade paroxística lenta, e espícula-onda lenta de $3 \mathrm{c} / \operatorname{seg}^{21}, 22,27,36,37$.

$O$ diagnóstico é baseado na dosagem de fenilalanina sérica; contudo o método exige laboratório especializado, com técnicas elaboradas e é dispendioso. Como recurso prático usa-se o teste de cloreto férrico, de fácil execução: em uma fralda ou papel de filtro umedecidos com urina fresca, pingase uma gota de cloreto férrico a $10 \%$, sendo positiva a reação se aparecer coloração azul-esverdeada ou cinza-esverdeada. No teste da dinitrofenil-hidrazina ( $1 \mathrm{ml}$ de urina fresca $+1 \mathrm{ml}$ da substância, agitar e deixar descansar durante 10 minutos) a reação será considerada positiva se aparecer um precipitado branco. Mais recentemente, Guthrie e Susi ${ }^{28}$ desenvolveram uma prova de triagem sangüinea, baseada no conhecimento de que a inibição de crescimento do bacilo subtillis pela B-2-tienilalanina em cultura, é evitada pela adição de fenilalanina, ácido fenilpirúvico e ácido fenil-lático; o teste será considerado positivo se, após colocação de sangue em pequenos discos de papel de filtro, houver crescimento do bacilo. Contudo, tôdas estas provas não dão um diagnóstico definitivo, pois outras condições poderão fornecer resultados semelhantes. A confirmação será feita mediante dosagem da fenilalanina sérica.

Diferentes tentativas de tratamento foram feitas com a finalidade principal de prevenir ou melhorar a deficiência mental. Resultados satisfatórios foram conseguidos com tratamento à base de dietas pobres em fenilalanina, sendo demonstrado que a instituição precoce da dieta pode evitar a deficiência mental ${ }^{11}$. Após os 3 anos de idade, os resultados são menos compensadores; o Q.I. não é muito influenciado.

\section{Moléstia de Hartnup (triptofanúria congênita).}

Baron e col. ${ }^{1}$, em 1956, descreveram a doença numa familia inglêsa de nome Hartnup. Em 1966, Jepson ${ }^{3}$ coletou 23 casos descritos, a maioria em paises europeus. Em 1969, Lopez e col. ${ }^{4}$ publicaram os dois primeiros casos observados no continetnte sul-americano. A moléstia é transmitida com caráter autossômico recessivo. 
A moléstia é devida a alteração no sistema de transporte de determinados ácidos aminados para as células. Ao que parece, os aminoácidos são reabsorvidos, ao nivel do glomérulo renal, por quatro fatôres específicos do epitélio tubular proximal, um dêles atuando sôbre um grupo de 13 ácidos aminados neutros. Na doença de Hartnup êstes ácidos aminados neutros são reabsorvidos de modo incompleto e a urina contém valóres elevados de cada um dêles ", $:$

Do mesmo modo que o epitélio tubular, a mucosa jejunal está preparada para a absorção de várias substâncias do conteúdo intestinal, nela existindo os quatro fatôres encontrados no epitélio tubular. Na doença, os 13 ácidos aminados excretados em excesso pela urina, são absorvidos de maneira insuficiente no jejuno ${ }^{8}$, o mesmo acontecendo em relaçăo ao triptofanos; a absorção insuficiente no instetino delgado faz com que quantidades anormais de triptofano alcancem o colo, onde a flora bacteriana produz indol, triptamina, ácido indolacético e outros produtos que são absorvidos. O indol é oxidado no fígado e excretado como sulfato de indoxil; a triptamina é oxidada e transforma-se em ácido indolacético, que é eliminado livre e parcialmente combinado com o ácido glucorônico ou glutamina. Taxas anormais destas substâncias estão presentes na urina dos pacientes. Por outro lado, o triptofano é normalmente metabolisado por diferentes mecanismos sendo uma parte transformada em nicotinamida que forma parte de co-enzimas cujo papel é fundamental em vários processos de oxidação. A absorção de triptofano sendo insuficiente e sendo exagerada a sua eliminação pela urina, o paciente com moléstía de Hartnup llca privado da fonte de nicotinamida.

As manifestações clínicas caracteristicas são alterações da pele, de tipo pelagra, e crises de ataxia cerebelar. Os distúrbios mentais são raros, variando entre modificações emocionais e alucinações. As manifestações pelagróides em geral aparecem nas áreas expostas do corpo e se acentuam pela exposição ao sol. O sinal neurológico mais constante é a ataxia que ocorre por períodos transitórios, sendo acompanhada de nistagmo e tremor das mãos. Ao que parece, as manifestações neurológicas podem ser desencadeadas por processos febrís ${ }^{1}$ e pela administração de sulfas ${ }^{2}$. A evolução da moléstia é lenta e a tendência é para a melhora dos sintomas com o passar do tempo.

A cromatografia urinária demonstra excreção elevada de alanina, serina, glutamina, valina, leucina, isoleucina, fenilalanina, tirosina, triptofano, histidina e citrulina. Os derivados do triptofano - indicão, ácido indolacético e ácido indol-láctico - estão aumentados na urina.

Quanto ao tratamento, resultados satisfatórios têm sido obtidos com o emprêgo de ácido nicotínico e dieta rica em proteínas.

Moléstia da urina com odor de xarope de bôrdo (hiperaminoacidúria com odor de xarope de bordo; citoaciduria de cadeia ramificada; deficiência carboxilásica; leucinose).

A doença foi caracterizada por Menkes e col. ${ }^{8}$ em 1954, ao descreverem quatro casos de irmãos que morreram de uma doença neurológica progressiva nas primeiras semanas de vida. A doença foi identificada como um distúrbio do metabolismo acidaminado por Westall e col. ${ }^{12}$ que encontraram valôres elevados de três ácidos de cadeia ramificada - leucina, isoleucina e valina - bem como de metionina. $O$ exato ponto do bloqueio metabólico foi subseqüentemente determinado em 3 diferentes laboratórios $5,6,7$. A doença é de 
caráter genético, transmitida por um gene autossômico recessivo. Não parece ter preferência racial. Buckup e col. ${ }^{1}$ publicaram o primeiro caso no Brasil, em 1963.

Normalmente os amino-ácidos de cadeia allfática composta (leucina, isoleucina e valina) são desaminados e transformados em ceto-ácldos que são ellminados pela urina ou fixados nos tecídos. O bloqueio metabólico compreende a fase imediata, ou seja, a decarboxilação oxidativa dos ceto-ácidos. Como a reação de transaminação é reversivel, ésses ceto-ácidos são retransformados em leucina, isoleucina e valina. Tal fato explica a auséncia e o aparecimento tardio, em alguns casos, dêsses aminoácidos na urina, quando a elíminação dos compostos cetônicos já é elevada. o defeito na decarboxilação, ao que parece, mobiliza mecanismos metabólicos anômalos; a decarboxilacão do ácido alfa-ceto-butírico produziria o ácido alfa-hidroxi-butirico, responsável pelo odor caracteristico da urina. O metabolismo do triptofano está secundàriamente comprometido, resultando no aparecimento de seus derivados na urina.

O acúmulo dos ácidos aminados, principalmente da leucina e de seus metabolitos intermediários normais e anormais, seria o responsável pela disfunção cerebral, através do efeito tóxico direto dessas substâncias ou de sua interferēncia nas reaçōes metabólicas cerebrais, como na sintese dos cerebrósídes. Por outro lado, os alfa-ceto-ácidos e os alfa-hidroxi-ácidos derivados da leucina e da valina inibem a atividade da decarboxllase do ácido 1-glutâmico, impedindo a formação do ácido gama-aminobutírico, importante regulador das funções cerebrais ${ }^{11}$.

Os estudos anátomo-patológicos sâo ainda restritos a alguns casos ${ }^{8},{ }^{\circ}$. Além da degeneração gordurosa do figado, fôram observados edema e degeneração dos rins e edema cerebral. As alterações do cérebro sāo limitadas à substância branca que apresenta defíciéncia de mielinização, aspecto esponjoso, redução da oligodendroglia e astrocitose; a microglia não mostra alterações. Em alguns casos, há fagócitos com depósitos de lípides nos espaços fibrosos perivasculares, mas não na substância branca.

Os sintomas aparecem logo após o nascimento, em geral no fim da primeira semana. Surge anorexia, a criança deixa de mamar e apresenta respiração irregular; surgem vômitos e letargia. O desenvolvimento da criança é interrompido, aparecem espasmos musculares, que alternam com periodos de hipotonia, e crises convulsivas. A urina apresenta o odor caracteristico já na primeira semana, e que tem sido descrito como de "malte", de "açúcar caramelado" e de "xarope de bôrdo". Crises hipoglicêmicas podem ocorrer 2 . A maioria dos pacientes não tratados evolui para a morte em poucas semanas. Contudo a gravidade da doença é variável e alguns pacientes sobreviveram, embora com déficit mental.

Os exames de laboratório confirmarão as suspeitas clínicas. Existe elevação das taxas de leucina, isoleucina, valina e aloisoleucina no sangue e na urina. A cromatografia da urina revela grande aumento dos ceto-ácidos e lfa-hidroxi-ácidos correspondentes. A cromatografia do liquido cefalorraqueano mostra aumento de leucina, isoleucina, valina e aloisoleucina ${ }^{10}$. Esses produtos aparecem aumentados também nas fezes ${ }^{5}$. Em alguns casos existe aumento do ácido fenilpirúvico e de fenilalanina na urina. A cromatografia mostra, ainda, aumento dos ácidos indol-acético e indol-lático e diminuição da tirosina, indicando alteração secundária no metabolismo do triptofano. Mackenzie e Woolf ${ }^{6}$ referem taxa reduzida da glicemia em jejum. 
A prova do cloreto férrico fornece resultado inespecífico, dando coloração verde-amarelada, devida à presença dos alfa-hidroxi-ácidos. A adição de 2,4-dinitro-fenilhidrazina à urina, precipita os ácidos cetônicos, sob a forma de hidrazonas. A adição de ácido sulfúrico diluído à urina fresca pode realçar o cheiro característico.

Desde que a doença é devida a alterações no metabolismo dos ácidos aminados de cadeia ramificada, as tentativas de tratamento são baseadas no uso de dietas livres dessas substâncias. A dieta "sintética" (Snyderman e col. ${ }^{10}$ ) é de difícil execução, porém seus resultados são animadores; ela representa o único recurso para melhorar o quadro clínico, evitando a evolução para a deficiência mental e morte.

\section{Sindrome de Lowe (síndrome óculo-cérebro-renal).}

Descrita em 1952, por Lowe e col. ${ }^{6}$, esta afecção é caracterizada por deficiência mental, catarata, glaucoma, hipotonia com arreflexia tendinosa e nefropatia tubular, sendo transmitida com caráter recessivo ligado ao sexo. Já na descrição original os autores relatavam acidúria orgânica e diminuição na formação de amonia pelo rim. A acidúria foi atribuída à excreção exagerada de amino ácidos e desde que a concentração dêsses sub-produtos no plasma era normal, foi admitida a presença de uma alteração renal ${ }^{4}$.

Schwartz e col. ${ }^{8}$ relataram os estudos bioquimicos realizados em uma familia: a aminoacidúria era aumentada pela administração de ornitina, mas não se alterava pela ingestão de outros amino-ácidos. A mãe dos pacientes respondia de maneira semelhante e os autores concluiram que a sindrome fôsse devida a uma anormalidade especifica do metabolismo da ornitina. Sidbury e Mac Carty ${ }^{9}$ obtiveram resultados semelhantes em um paciente, mas em outro a ornitina não provocou aumento de aminoacidúria, o que os levou a concluir que deveria existir mais de uma alteração metabólica. Chutorian e Rowland ${ }^{4}$ estudaram o metabolismo de um paciente e de seus pais, obse vando falta de uniformidade no tipo de excreçāo dos amino-ácidos, aumento da aminoacidúria após ingestão de diferentes aminoácidos, inclusive a ornitina, emitindo a opinião de que a sindrome seja devida a uma alteração renal e não ao defeito metabólico de um único amino-ácido.

Os estudos anátomo-patológicos não têm mostrado a existência de lesões específicas em qualquer dos órgãos afetados. Os rins mostram dilatação tubular e degeneração do epitélio ${ }^{2},{ }^{7}$, e podem estar atróficos, com dilatação dos cálices contendo múltiplos cálculos de côr amarelada; os glomérulos podem apresentar esclerose e hialinização. As alterações cerebrais têm sido variáveis, sendo encontradas desmielinização difusa, degeneração esponjosa e esclerose gliofibrilar. Hooft e col. ${ }^{3}$ encontraram alterações do cristalino, assim como anomalias congênitas da porção anterior da retina e do corpo ciliar.

Clinicamente o atraso da motricidade é considerável: o lactente mantémse inerte, sendo incapaz de sustentar a cabeça; não raramente, apresenta agitação incessante e desordenada. A hipotonia é extrema, acompanhada de hiperrelaxação ligamentosa e abolição de reflexos osteotendinosos. O desenvolvimento psíquico é baixo e a catarata constante, quase sempre bilateral. Glaucoma ocorre em $50 \%$ dos casos, sempre bilateral, podendo ser congê- 
nito ou aparecendo na evolução da doença. O fácies é característico: criança loura, pálida, com trama venosa superficial, proeminência da fronte e órbitas escavadas. A nefropatia causa acidose hiperclorêmica. Sinais raquitiformes com transparência óssea exagerada e fraturas espontâneas têm sido mencionados.

\section{Moléstia de Lesch-Nyhan.}

Esta doença, transmitida por um gene ligado ao cromossomo, é caracterizada por retardo mental, movimentos córeo-atetósicos, espasticidade dos membros inferiores que assumem a atitude "em tesoura", auto-mutilação e hiperprodução de ácido úrico. A automutilação não é devida a analgesia congênita mas a impulsos de agressividade, incontroláveis, e que podem ser dirigidos contra outras pessoas. O ácido úrico apresenta-se elevado no sôro, em taxas comparáveis às encontradas na gôta $(10 \mathrm{mg} / 100 \mathrm{ml})$ e a excreção diária chega a $1 \mathrm{~g}$.

O defeito enzimático consiste na ausência de atividade da hipoxantina-guaninafosfo-ribosiltransferase, demonstrada em eritrócitos e fibroblastos. Essa enzima é de grande importância para a ressintetização de purinas que são normalmente catabolisadas e excretadas como ácido úrico. O mecanismo de reutilização conserva parte da hipoxantina que é transformada em ácido inosínico e da guanina transformada em ácido guanítico. $\mathrm{Na}$ ausência dêsse mecanismo de reutilização da hipoxantina e guanina, surge incapacidade de manutenção dos niveis necessários de nucleótides para a inibição retrógrada da sintese de purinas. Assim, as purinas são sintetizadas em demasia e o ácido úrico é eliminado em excesso.

E surpreendente que a ausência de atividade dessa enzima produza as grandes manifestaçōes neurológicas da doença de Lesh-Nyhan, enquanto a sintomatologia da maioria dos pacientes com gota, apresentando deficiência significativa dessa atividade (90 a $95 \%)$, seja tão discreta.

\section{DISTURBIOS DO METABOLISMO DOS LIPIDES}

Moléstia de Gaucher (esplenomegalia idiopática; hepatoesplenomegalia por células lipidicas).

A doença é devida a acúmulo anormal de cerasina nas células do sistema reticulo endotelial, do fígado, baço, medula óssea e gânglios linfáticos e, ocasionalmente, no sistema nervoso central ${ }^{6}, 11,12$. É moléstia familial, de ocorrência autossômica recessiva na maior parte dos casos. Apresenta a forma infantil e a forma do adulto.

Sob o título de "epitelioma primitivo do baç" Gaucher descreveu, em 1882, a moléstia que hoje tem seu nome. Em 1924, Epstein ${ }^{2}$ e Lieb ${ }^{4}$ demonstraram que a substâncla depositada é um cerebróside (cerasina). Em 1926, Pick fêz a distínção entre a moléstia de Niemann-Pick e a de Gaucher; no ano seguinte, Ubberling e Woringer $^{7}$ descreveram a forma neurológica infantil da doença, com o mérito de terem demonstrado que a afecção é uma cerebrosidose reticular.

Nesta doença os órgãos contém concentração elevada anormal de cerebróside; tal acontece também com 0 cérebro, mas em menos intensidade ${ }^{6}$. No cérebro 
normal a galactose é a hexose do cerebróside ao passo que, na moléstia de Gaucher, um terco da hexose é glicose. Ao que parece, existe deficiência da glicocerebrosidase, que transforma a glicosilceramida em glicose e ceramida, com resultante retenção dessas substâncias.

A caracteristica principal é a presença das células de "Gaucher" nos órgāos retículo-endoteliais, no fígado, baço e gânglios linfáticos. Estas células são histiócitos volumosos, com citoplasma pálido e reticular, que se apresentam cheias de cerasina. As alteraçōes do sistema nervoso central são, geralmente, discretas; pode haver discreta atrofia cerebral e neurônios podem aparecer retraídos, ou mostrar granulaçōes que, segundo Schairer ${ }^{10}$, sugerem cerasina. Em poucos casos, as células de Gaucher têm sido observadas nos espaços perivasculares e no côrno anterior da medulas. A substância branca pode mostrar acúmulo de macrófagos, carregados de lipides; nos espaços perivasculares a cerasina intracelular dá reação PAS positiva.

Adoença se inicia até os 6 primeiros mêses de vida, e a gravidade dos sintomas neurológicos está na razão direta da época de instalação da moléstia. Geralmente, a criança passa bem as primeiras semanas ou o primeiro mês de vida; surgem, então, distúrbios gastrintestinais e retardo do desenvolvimento psicomotor. O abdome aumenta de volume devido à hepatosplenomegalia. Os gânglios linfáticos tornam-se infartados. Surge hipotonia muscular que, aos poucos, é substituída por espasticidade, acompanhada de contraturas. Podem ocorrer paralisias de músculos oculares. Crises tônicas, tônico-clônicas ou mioclônicas são observadas. A deterioração mental progride, aparece rigidez decerebrada, opistótono, disfagia, espasmos laríngeos, dispnéia e cianose. A morte sobrevém durante uma crise de cianose ou por infecção intercorrente, em geral de 4 a 8 mêses após a instalação da doença.

Exames radiológicos podem revelar descalcificação difusa, bem como áreas circunscritas de rarefação, resultantes de necrose asséptica. Pode haver discreta anemia normocítica e leucopenia com relativa linfocitose. A fosfatase ácida pode estar elevada no sôro. Em poucos casos é observada trombocitopenia. O diagnóstico de certeza é feito pela identificação das células de Gaucher na medula óssea ou mediante biópsia hepática ou esplênica.

\section{Idiotias Amauroticas.}

São doenças genéticas familiais, transmitidas em geral com caráter receșsivo, não mostrando preferência por qualquer dos sexos. A consangüinidade é verificada em $40 \%$ dos casos. Acredita-se atualmente que estas doenças, em tôdas as suas formas, têm origem em alterações enzimáticas que ocorrem ao nível celular, interferindo no metabolismo geral dos lípides. Contudo, a exata natureza do distúrbio enzimático permanece ainda desconhecida.

O cérebro apresenta, na maioria dos casos, atrofia generalizada, mas discreta; a atrofia dos nervos ópticcs é evidente; a do cerebelo variável. A lesão caracteristica é representada pelas modificações dos neurônios, que estão aumentados de volume, com forma de balão, sendo o núcleo deslocado para a periferia. Nos cortes em congelação, o corpo celular aparece impregnado por um material granuloso que se cora de amarelo claro pelo vermelho-escarlate, de rosa pelo PAS e, de vermelho, 
pelo sublimado de Cajal; o material não é birrefrigente e não enegrece pelo ácido ósmico.

Ao lado do processo de armazenamento lipidico, surgem fenômenos degenerativos, com células pequenas, retraídas, contendo um ou dois núcleos picnóticos. As alterações celulares são observadas em todo o sistema nervoso, inclusive no tálamo, cerebelo, tronco cerebral, retina e nas células ganglionares periféricas.

As lesōes retinianas têm interêsse particular. Nas formas infantis, os cones, os bastonetes, as camadas nucleares externa e interna têm aspecto normal, enquanto a região macular e as células da cámada ganglionar são volumosas devido ao acúmulo de lípides. Nas formas juvenis, o comprometimento é maior; além das células ganglionares se apresentarem com depósitos anormais, surgem lesões degenerativas da camada nuclear externa, dos cones e bastonetes, com desaparecimento dos elementos celulares.

Os depósitos de lípide estão restritos, em princípio, às células nervosas. Excepcionalmente têm sido observados no fígado, rins e pulmōes ${ }^{5}{ }^{15}$. A identificação da substância armazenada nas células foi feita por Klenk ${ }^{9}$, que demonstrou tratar-se de um ganglióside (esfingolipide do grupo dos glicoesfingósides) formado de um ácido graxo, de uma hexose, de esfingosina, de hexosamina e de ácido neuraminico.

Na forma infantil (Idiotia amuurótica familial de Tay-Sachs), o desenvolvimento é normal até o terceiro ou sexto mês de vida. A criança torna-se, então, apática e não responde a estímulos, não mantém a cabeça, não muda de posição na cama; os membros tornam-se flácidos. Há retardo acentuado ou mesmo interrupção do desenvolvimento motor. Os músculos se atrofiam, as paralisias se acentuam, surgem contraturas e a evolução se faz para rigidez decerebrada. A visão se reduz gradativamente. Os reflexos profundos tornam-se exaltados e aparece o sinal de Babinski. Convulsões podem ocorrer. Na maioria dos casos, a reação à luz é conservada, apesar da amaurose. O exame dos fundos oculares mostra mancha circular ou ovalar, de côr branco-acinzentado, que ocupa a mácula, com um ponto côr-de-cereja ou marron-avermelhado no centro. O nervo óptico apresenta-se pálido e atrófico. Os movimentos oculares em geral estão preservados, podendo surgir nistagmo ou movimentos rotatórios da cabeça ${ }^{6}$. A evolução da moléstia é progressiva e inexorável; não existe na literatura qualquer referência à sobrevida. A morte ocorre, principalmente por infecções intercorrentes, após uma evolução de 2 a 3 anos.

$\mathrm{Na}$ foma infantil tardia ou juvenil precoce (Bielschowsky-Jansky), o início da moléstia se dá entre 3 e 5 anos de idade, sendo a evolução bem mais lenta que na forma infantil. Ataxia e sinais cerebelares são comuns, mas a mancha-cereja não é observada na retina; contudo, a acuidade visual diminui progressivamente por atrof:a óptica; a região da mácula apresenta sinais de atrofia e aparece com pigmentação escura. Outros sinais podem surgir: estrabismo, nistagmo, pupilas preguiçosas, hipoacusia. A deterioração mental é progressiva e surgem crises convulsivas, espasticidade e contraturas ${ }^{i}, 16$.

$\mathrm{Na}$ forma juvenil (Spieimeyer-Vogt), a moléstia se inicia entre os 6 a 9 anos de idade tendo, como primeira manifestação clínica, a diminuição da visão. O exame ocular mostra a mácula de coloração pálida, rodeada por 
uma zona de pigmentação marron-escura, que é envolta por outra área de côr avermelhada. A lesão pode ser restrita à mácula ou estender-se para a periferia e atingir outras áreas de retina. Os vasos podem estar filiformes, as artérias e veias apresentando o mesmo calibre. A mancha-cereja não é observada ${ }^{4}$. Vários anos após o aparecimento das alterações retinianas, surgem convulsões, alterações mentais e, ulteriormente, deterioração mental. A fala torna-se escandida, surge ecolalia. Podem ocorrer episódios de riso e chôro imotivados. Tremores, rigidez e diminuição dos movimentos associados podem ser evidentes. O quadro final é de idiotia com rigidez, grandes atrofias e fraqueza muscular. Eventualmente, instala-se tetraplegia espástica. A morte sobrevém 10 a 15 anos após a instalação dos primeiros sintomas, devida a infecções intercorrentes ou a estado de mal epiléptico.

$N a$ forma juvenil tardia (Kufs), a moléstia se manifesta entre os 15 e 25 anos. Os sinais mais importantes são déficit intelectual, com deterioração gradativa, incoordenação muscular, ataxia, rigidez e tremor. Nesta forma nunca foram descritas perturbações visuais, nem alterações da retina e nervos ópticos. Nos casos publicados por Kufs, um ou mais ascendentes parecem ter sofrido lesōes retinianas típicas, mas sem terem apresentado retardo mental ou distúrbios motores ${ }^{8}, 16$. O diagnóstico desta forma clínica é difícil e sua inclusão entre as esfingolipidoses só se justifica pela semelhança que as lesões anatômicas apresentam com as das formas infantil e juvenil; os depósitos lipídicos são menos intensos e restritos a certos territórios.

A forma congênita foi descrita por Norman e Wood ${ }^{10}$, em 1941, ao estudarem uma criança com 18 dias de vida, pertencente a uma familia de raça não judia e na qual foram encontrados, mais tarde, dois outros irmãos com alterações semelhantes. Contudo, a inclusão dêsses casos entre as esfingolipidoses é discutivel, pois embora os depósitos lipídicos nas células fossem maciços, a substância branca estava impregnada de cristais extra-celulares de colesterol. O próprio Norman admite que seus casos não correspondem ao quađro anátomo-patológico e bioquímico da idiotia amaurótica.

Moléstia de Niemann-Pick (esfingomielinose reticular e histiocitária; lipoidose fosfatídica).

É moléstia rara, atingindo preferentemente a raça judia. E de caráter hereditário e familial, com transmissão de tipo autossômico recessivo, com consangüinidade dos pais em cêrca de $12 \%$ dos casos. $\mathrm{Na}$ maioria dos casos, a doença se inicia antes dos dois anos, embora alguns casos tenham sido descritos em fetos e natimortos ${ }^{1}$. A evolução é progressiva, deteriorante, mas há casos com sobrevida até 20 anos.

Em 1914, Niemann relatou o caso de criança de origem judia, cuja moléstia consistia principalmente em esplenomegalia e mau estado geral; a pele era sêca, a face apresentava coloração marron e o abdome distendido permitia a palpação do figado e baço, como se fossem dois tumores volumosos. O exame anátomo-pato- 
lógico mostrou o baço aumentado de volume, com nódulos amarelo-esbranquiçados; o figado estava hipertrofiado e duro; os gânglios linfáticos, os rins e as adrenais apresentavam aspecto idêntico; microscòpicamente foi verificada a presença de grandes depósitos de lípides. A observação de Niemann passou desapercebida até que Pick, em 1927, estudou novos casos e identificou a doença como uma afecção familiar e congênita, atingindo preferentemente o sexo feminino e desenvolvendo-se durante a primeira infância; do ponto de vista bioquimico, verificou lipemia e, na maioria dos casos, hipercolesterenemia.

A doença é devida a distúrbio constitucional do metabolismo celular dos histiócitos e das células reticulares ao nivel de todos os órgãos, levando à deposição de uma esfingomielina; as monoaminas (lecitina e cefalina) nāo sofrem alteraçōes ${ }^{6}$. Mais recentemente, tem-se admitido que a esfingomielina é depositada nos órgãos sob a. forma de lipoproteinas ${ }^{5}$.

A doenca caracteriza-se pelo aparecimento das chamadas células de NiemannPick, formadas de células reticulares e histiócitos, em pràticamente todos os órgãos, especialmente no fígado e baço; o sistema reticulo-endotelial, os pulmões, rins, sistema nervoso, coração e mesmo glândulas endócrinas aparecem carregadas destas células que têm aspecto esponjoso, contendo depósitos de esfingomielina. O colesterol também apresenta-se aumentado nos tecidos, em especial no fígado e baço. O encéfalo, o cerebelo e a medula apresentam depósitos disseminados de esfingomielina, bem como de gangliósides e colesterol nos neurônios e células gliais. Os grandes neurônios tornam-se distendidos, assumindo aspecto semelhante àquele das células observadas na idiotia amaurótica e no gargulismo. Contudo, na doença de Niemann-Pick, existem depósitos de lipide no endotélio dos vasos, nas células da aracnóide e macrófagos no plexo coróide. Podem ocorrer destruiçāo neuronal e atrofia cerebral, associadas à gliose. Muitas células contém grânulos de gordura neutra, sendo intensos os distúrbios na mielinização. Lesões da retina ocorrem em cêrca de 50\% dos casos, devido ao acúmulo de lipides; a degeneração das células ganglionares e o adelgaçamento da camada neuronal nas margens da fóvea tornam a camada cório-capilar mis evidente, produzindo a mancha-cereja, tal como na idiotia amaurótica.

Depois de um periodo de alguns meses em que o desenvolvimento é normal, a criança perde o apetite, apresenta dificuldades para se alimentar e perde pêso. Contrastando com o aspecto do tórax, fino e edemaciado, o abdome aparece aumentado de volume e distendido, com o fígado e baço fàcilmente palpáveis. A pele apresenta áreas de coloração marron e aspecto céreo. Os gânglios linfáticos aumentam de volume. Gradativamente, a criança torna-se apática, os olhos desviam-se para cima, a boca permanece aberta, a língua em protrusão e, em pouco tempo, fica imóvel na cama. A visão diminui progressivamente, podendo chegar à cegueira, com atrofia óptica e da retina. Pode surgir nistagmo. Em alguns casos desenvolve-se surdez. Podem surgir paralisias flácidas ou espásticas. Na fase final aparece demência grave.

Nos últimos anos o conceito da moléstia de Niemann-Pick tem-se modificado e a tendência atual é considerá-la não como uma única entidade clínica e bioquímica, mas reunindo, pelo menos, quatro condições ${ }^{2,3,4}$. Assim, cêrca de $85 \%$ dos pacientes estariam incluídos no chamado grupo $A$, que corresponde à descrição clássica de Niemann-Pick. No grupo B, correspondendo à forma visceral ou crônica, os pacientes não apresentam sintomatologia neurológica, apesar do comprometimento intenso dos órgãos viscerais. Nos pacientes do grupo $\mathrm{C}$ a moléstia tem evolução lenta e as manifesta- 
ções neurológicas, quando presentes, aparecem entre os 2 e 4 anos de idade. O grupo D, chamado de "grupo da Nova Escócia", é caracterizado por evolução clínica ainda mais lenta, os sinais neurológicos aparecendo durante a primeira ou segunda infância; os pacientes não apresentam aumento da esfingomielina cerebral e os depósitos dêsse material no fígado e baço não são tão evidentes; por outro lado, as taxas de colesterol não esterificado são 6 a 10 vêzes maiores que os valôres normais.

Os exames bioquímicos são, às vêzes, discordantes. O aumento das taxas de lipemia total e do colesterol, considerado como dado clássico, é inconstante. A elevação da fosfatase ácida não tem sido confirmada por todos os autores. As transaminases séricas e a aldolase aparecem aumentadas, ao contrário do que acontece com a lactodesidrogenase. Os exames hematológicos são de valor mais imediato. A presença de linfócitos e monócitos vacuolisados tem sido confirmada na maioria dos casos. O recurso mais importante é o encontro das células de Pick na medula óssea, nos gânglios linfácitos ou em material hepático.

\section{Leucodistrofias}

As leucodistrofias foram, durante muito tempo, incluídas no grande grupo das escleroses cerebrais difusas, em virtude da extensão do processo desmielinisante e esclerosante a tôda a substância branca. Contudo, devido ao seu caráter hereditário e familial passaram a ser consideradas em grupo a parte; atualmente são incluídas no capítulo das moléstias metabólicas do sistema nervoso, com substrato conseqüente a distrúbios no metabolismo da mielina. Do ponto de vista histopatológico, caracterizam-se por desmielinização difusa e quase sempre simétrica dos hemisférios cerebrais e cerebelares.

Segundo os estudos de Collier e Greenfield ${ }^{10}$ as leucodistrofias compreendem 3 tipos fundamentais: $a$ ) de células globóides (forma de Krabbe); $b$ ) metacromática (forma de Scholz); $c$ ) de tipo sudanófilo (forma de PelizaeusMerzbacher). Estes três tipos compreendem várias formas descritas anteriormente por diferentes autores: forma infantil aguda (Krabbe), juvenil subaguda (Scholz), do adulto (Ferraro), crônica (Pelizaeus-Merzbacher) e tardia do adulto (van Bogaert e Nyssen).

Os sintomas correspondem a uma enfermidade de evolução progressiva, com interrupção das conexões entre o córtex cerebral e centros subjacentes do neuro-eixo e que se traduz, clinicamente, por grande variedade de manifestações, tanto na criança como no adulto. O início da moléstia é, em geral, caracterizado por marcha atáxica ou espástica. Simultâneamente ou após curto período de tempo, surgem os distúrbios mentais, ràpidamente seguidos por apatia. A fala é alterada e crises de riso e chôro espasmódico são freqüentes. Paralisias espásticas instalam-se progressivamente e evoluem para a tetraplegia. Desenvolvem-se crises tônicas que são desencadeadas por qualquer estímulo sensorial. Crises convulsivas, movimentos córeo-atetósicos e nisțagmo podem aparecer. A morte sobrevém por caquexia ou por infecções intercorrentes ou, ainda, por distúrbios bulbares. 
Deve ser ressaltado, no entanto, que a variação dos sintomas é muito grande, bem como a ordem cronológica de seu aparecimento. Formas psíquicas puras podem ocorrer em adultos. As formas de evolução rápida são mais comuns nas crianças jovens e, as de longa duração, nos adolescentes e adultos.

Embora ainda não se disponha de recursos terapêuticos contra as leucodistrofias, a necessidade do diagnóstico precoce se justifica, do ponto de vista prático, para aconselhamento genético.

O primeiro caso de leucodistrofia por células globóides (Krabbe) foi descrito por Beneke, em 1908. Em 1916, Krabbe publicou descrição completa de dois irmãos que faleceram aos 13 e 12 mêses de idade e, desde então, o epônimo "tipo de Krabbe" tem sido usado para os casos familiares de esclerose difusa com início na idade infantil precoce. Mas, Blackwood e Cumings ${ }^{6}$ e Diezel ${ }^{13}$ restrigiram a denominação aos casos em que as células epitelióides ou globóides são proeminentes.

Nos casos com evolução superior a um ano existe completa desmielinização da substância branca de um ou mais lobos cerebrais. Os lobos occipitais são os mais freqüentemente comprometidos. A substância branca do cerebelo está geralmente comprometida, bem como a do bulbo, no qual as lesões sāo, por vêzes, restritas a alguns tractos. Assim, os pedúnculos cerebelares médios, a substância branca dos hemisférios cerebelares e as fibras olivo-cerebelares podem estar desmielinizadas, enquanto o núcleo denteado e o pendúnculo cerebelar superior permanecem intactos.

Com freqüência existe aumento celular em áreas de desmielinização recente; tais células são de médio-tamanho, redondas ou ovais, mononucleadas, com corpo celular finamente granular e núcleo oval e não tão hipercromático como os fagócitos carregados de lípides que estão na mesma área. Em alguns pontos estas células epitelióides são numerosas, 20 ou 30 , em geral se dispondo ao redor de um pequeno vaso. Outras células maiores são encontradas isoladas, medindo de 20 a 50 micra, e de forma esférica; possuem de 2 a 15 núcleos e podem apresentar vacúolos, mas nunca assumem o aspecto esponjoso. Estas células foram chamadas de globóides (Collier e Greenfield ${ }^{10}$ ).

As reações das cólulas globóides e epitelióides a distintos corantes são semelhantes; admite-se hoje, que o material existente nestas células é um cerebróside do tipo encontrado na mielina, associado a proteína; o mesmo cerebróside é encontrado em taxas elevadas em tôda a substância branca, enquanto os valores dos ésteres sulfúricos dêsse lípide (sulfátides) e do colesterol estão diminuidos. A origem das células epitelióides e globóides ainda é discutida. Blackwood e Cumings ${ }^{\circ}$ acreditam que se formam à custa da microglia, Ferraro ${ }^{1 \tau}$ e Pfeiffer ${ }^{28}$ defendem a origem astrocitária e Norman ${ }^{28}$ crê na origem histiocitária.

A leucodistrofia de tipo sudanófilo (Pelizaeus-Merzbacher) é caracterizada como uma forma familiar, lentamente progressiva, de esclerose cerebral difusa. A doença é transmitida como caráter recessivo, através de mulheres sadias, com maior tendência a atingir os homens que as mulheres.

A doença se inicia na infância, mas sua evolução é tão lenta que muitos pacientes chegam à terceira década. A instalação se traduz por parada do desenvolvimento psico-motor, com deterioração mental lentamente progressiva. Os distúrbios da fala são representados por bradilalia com disartria. Surgem movimentos involuntários anormais - tremor intencional, córeo-atetose 
- logo aparecem os sinais cerebelares e nistagmo. Crises convulsivas podem surgir em fases tardias, bem como diminuição ou perda de visão.

Existe desmielinização difusa do sistema nervoso central, com retração do centro semi-oval e dilatação dos ventriculos. A desmielinizaçāo é incompleta, deixando ilhotas de fibras nervosas e bainhas de mielina intactas, particularmente ao redor dos pequenos vasos. Os hemisférios cerebelares também estão desmielinizados e retraidos. O tronco cerebral e a medula mostram destruição da mielina e, em geral, o tracto córtícospinal é o mais atingido. A desmielinização é acompanhada de gliose isomorfa e os axônios estão preservados. Do ponto de vista histoquimico, Blackwood e Cumings ${ }^{\circ}$ evidenciaram diminuiçāo global dos lipides cerebrais e ausência dos ésteres do colesterol. Steitelberger ${ }^{2 i}$ demonstrou que a bainha de mielina desaparece como estrutura morfológica, persistindo como bainha gordurosa que contém os lipides típicos (esfingomielina e cerebrósides). Contudo, mediante coloração da bainha de mielina, sòmente a lipido-proteina é identificada, sugerindo que os esfingolípides seriam preservados enquanto a fraçāo glicero-fosfatidica seria destruida. Assim, a forma de Pelizaeus-Merzbacher seria uma leucodistrofia com desmielinização do tipo sudanófilo.

Na leucodistrofia metacromática (Scholz) os distúrbios metabólicos da mielina estão relacionados, provàvelmente, a um defeito funcional congênito da neuroglia. Haberfeld e Spiller teriam sido os primeiros a descrever um caso desta enfermidade, em 1910, cujo estudo histológico foi realizado por Schilder, em 1913, que o incluiu entre as encefalites periaxiais difusas. Mas, foi Scholz em 1925, quem descreveu as bases genéticas e os caracteres morfológicos e clínicos da afecção. Canelas e col. ${ }^{8}$ fizeram excelente revisão do assunto ao estudarem cinco casos de leucodistrofia metacromática. Atualmente esta moléstia figura definitivamente entre as lipidoses (lipidose sulfatídica, Austin ${ }^{4}$; sulfatidose, Svennerholm ${ }^{28}$ ).

As áreas desmielinizadas contém granđe quantidade de lipides, na maioria extracelular, sob a forma de densas massas granulares ou corpúsculos esféricos que se coram em marrom pelo cresil-violeta (von Hirsch e Peiffer ${ }^{30}$ ). Este material metacromático, encontrado também no interior das células nervosas e no endotélio capilar das áreas desmielinizadas ${ }^{24}$, assim como em vários órgãos extranervosos e no sedimento urinário, é constituido por ésteres sulfúricos de cerebrósides, ou sulfátides. Além da substância metacromática, Diezel ${ }^{13}$ constatou a presença de um pigmento de natureza mucopolissacaridica no interior de células do núcleo denteado e do tronco cerebral e na substância branca. Nas formas do adulto, Diezel assinalou a presença de um complexo glicolipoprotēico. Foi verificado aumento de hexosamina e ácido neuramínico nas áreas lesadas. Contudo, embora essas substâncias sejam componentes dos gangliósides, Cumings ${ }^{12}$ não observou modificação dos niveis dêstes glicolipides na leucodistrofia metacromática.

Como o processo desmielinizante pode atingir qualquer porção do sistema nervoso, os quadros clínicos podem ser variados. De regra, contudo, as lesões se limitam ou predominam no cérebro e cerebelo, traduzindo-se, por tetraplegias espásticas progressivas, ataxia cerebelar e distúrbios mentais. Alterações visuais são muito freqüentes, ocorrendo atrofia óptica em grande parte dos casos infantis ${ }^{18}$, podendo-se mesmo encontrar a mancha macular vermeIho-cereja (Allen e col. ${ }^{1}$ ). Distúrbios gnósticos, apráxicos, hipercinesias e convulsões podem associar-se à tríade fundamental. A molèstia inicia-se ge- 
ralmente por distúrbios da marcha, em razão da espasticidade e/ou da ataxia; instalam-se distúrbios mentais, seguidos por apatia; a espasticidade se acentua, levando às tetraplegias com contraturas em extensão dos membros inferiores e, em flexão, dos superiores, compondo um quadro de rigidez descorticada. Periodos de melhora são obsrevados em alguns casos ${ }^{21}$.

Até há alguns anos, o diagnóstico era exclusivamente anátomo-patológico. Atualmente, porém, já é possivel firmá-lo durante a vida, com relativa segurança, mediante: $a$ ) verificação dos corpúsculos granulares metacromáticos na urina, usando o teste de Austin $^{2}$ com azul de toluidina; $b$ ) testes cromatográficos da urina, qualitativos ou semiquantitativos; $c$ ) aumento inespecífico do colesterol no sangue, concentração de sulfátides não diferindo da faixa normal ${ }^{18}$. No líquido céfalorraqueano, em casos infantís, é freqüente a elevação das proteínas totais; o perfil eletroforético, contudo, costuma ser normal, o que representa um subsídio de valor para a diferenciação entre os quadros periféricos da leucodistrofia metacromática e a polirradiculoneurite. O pneumencefalograma mostra atrofias corticais nos casos avançados. O estudo histoquímico de biópsias é de grande valor: em 9 biópsias cerebrais, $\mathrm{Cu}$ mings ${ }^{12}$ obteve confirmação em todos os casos, mediante métodos químicos. As biópsias de rim e fígado também contribuem para o esclarecimento diagnóstico. Canolas e col. ${ }^{8}$ comprovaram, em dois casos, a existência de corpúsculos granulares metacromáticos na saliva e no líquido cefalorraqueano, bem como em biópsia da parótida.

\section{Moléstia de Refsum}

Descrita, pela primeira vez, por Refsum, em 1945, que a denominou de "heredopathia atactica polyneuritiformis" ${ }^{8}$. Em 1949, Refsum e col. ${ }^{9}$ referiram a ocorrência da síndrome em crianças. Observaçōes diversas confirmaram a idéia original de Refsum de que a doença é hereditária e transmitida com caráter autossômico recessivo; a freqüência é semelhante em ambos os sexos.

Em 1961, Thiébaut, Lemoyne e Guillaumat ${ }^{15}$ relataram a observação de um paciente que sofria de uma afecção congênita e cujas características não correspondiam a qualquer moléstia descrita até a época da apresentação original, julho de 1939; tal quadro clínico, veio a ser considerado como correspondendo à descrição de Refsum. Por esta razão, autores francêses referem-se à entidade como moléstia de Refsum-Thiébaut.

As características clínicas mais importantes são: (a) retinite pigmentar atípica, com hemeralopia e redução concêntrica dos campos visuais; (b) quadro de polineurite crônica, com paresia progressiva das partes distais dos membros e diminuição ou ausência dos reflexos profundos; (c) ataxia e outros sinais cerebelosos; $(d)$ dissociação albumino-citológica no líquido cefalorraqueano; $(e)$ alterações eletrocardiográficas; $(f)$ alterações pupilares, como miose e resposta preguiçosa à luz; $(g)$ em alguns casos, hipoacusia de tipo neurogênico; $(h)$ anosmia; $(i)$ alterações cutâneas que lembram a ictiose; (j) em poucos casos têm sido observadas anomalias esqueléticas, como 
displasia epifisária simétrica das articulações do cotovelo, do ombro e joelho, pé cavo e encurtamento congênito e hiperdesenvolvimento de metacarpianos e metatarsianos. Como regra, o início é insidioso e, não raramente, parece ser desencadeado por infecções. A evolução é geralmente recidivante, com tendência à piora progressiva.

Uma das características mais constantes é o aumento de proteínas no líquido cefalorraqueano com contagem celular normal. Ashenhurst e col. ${ }^{2}$ fizeram estudos eletroforéticos repetidos das proteinas do LCR de um paciente e sòmente em uma ocasião observaram acentuada elevação das globulinas beta e gama. Spina-França e col. ${ }^{11}$ estudaram um paciente com forma incompleta de moléstia, não tendo observado a dissociação albumino-citológica no LCR, mas o proteinograma do sôro mostrava aumento de globulina alfa 2 ; como o paciente foi examinado durante fase de remissão da moléstia, os autores relembram a semelhança do caso com o descrito por Ashenhurst e col. ${ }^{2}$, que apresentava paralelismo entre o aspecto clínico e a taxa de proteínas do LCR. Outras alterações bioquímicas são observadas no sôro: elevação dos valores de ácidos graxos, cobre, ácido neuramínico, transaminases, ceruloplasmina, creatinoquinase e deidrogenase lática, e diminuição de colinesterase.

A doença parece ser devida a um êrro congênito do metabolismo lipídico, pelo qual as taxas de um ácido graxo, o ácido fitânico, aparecem anormalmente elevadas. Em 1963, Klenk e Kalhke ${ }^{\circ}$ identificaram um ácido graxo de cadeia ramificada, existente em concentrações elevadas nos tecidos de um paciente com sindrome de Refsum; êstes autores encontraram conteúdo elevado de gordura no fígado e nos rins que, ulteriormente, foi identificada como sendo o ácido fitânico. Tais achados foram ulteriormente confirmados.

Considerado, de início, como sendo um ácido "anormal" no organismo, o ácido fitânico foi identificado como elemento normal, presente em baixíssimas concentracões no sangue e tecidos de individuos sãos. A concentração no plasma é de cêrca de $2 \mathrm{mg} / \mathrm{ml}$ ao passo que, nos pacientes com moléstia de Refsum, alcança valores entre 50 a 500 vêzes a taxa normal. O ácido fitânico foi sintetizado a partir do fitol, que é o principal constituinte da molécula de clorofila. Como o ácido fitânico também é acumulado no fígado e no plasma de ratos alimentados com dietas ricas dêsse ácido, Alexander ${ }^{1}$ sugere que uma fonte exógena de fitol, como a clorofila, possa ser a precursora do ácido fitânico. Dados experimentais indicam que na doença de Refsum um defeito metabólico hereditário, possivelmente enzimático, impede a transformação do ácido fitânico, sintetizado a partir do fitol, em CO2; o ácido fitânico acumulado é, então, incorporado à bainha de mielina em formação.

Quando o fitol marcado é usado em pacientes com a moléstia, verifica-se que é transformado em ácido fitânico em poucas horas ${ }^{14}$. Uma prova indireta e, de grande interêsse terapêutico, é realizada pelo uso de dietas sem fitol (exclusão de vegetais e frutas verdes) e sem ácido fitânico (supressão de manteiga e gorduras animais); ocorre redução evidente nas concentrações sangüineas após um periodo de 6 a 12 meses ${ }^{13}$.

No sistema nervoso central as manifestações do metabolismo lipídico anormal são variáveis. As leptomeninges se apresentam espessadas e fortemente infiltradas por lípides. Na parede do epêndima, não apenas as células do epêndima, mas também os astrocitos subjacentes, estão cheios de gordura. No córtex cerebral, os vasos estão envolvidos por numerosos "macrófagos" carregados de lípides. Os neurônios aparecem aumentados de volume e infiltrados por granulações lipídicas (lipofucsina). $\mathrm{Na}$ maioria das vêzes tem sido observadas lesões do tronco cerebral. Destruição e 
lesōes degenerativas das células nervosas têm sido observadas nos núcleos olivares inferiores, na parte dorsal dos núcleos vestibular e coclear, no núcleo vagal, no núcleo denteado e no núcleo vermelho. Na medula há atrofía das fibras sensitivas das colunas posteriores. As células do corno motor anterior estão reduzidas em número, algumas mostrando sinais de degeneração retrógrada. Os nervos periféricos aparecem espessados, à custa do aumento de tecido conjuntivo endoneural. Alguns dos cilindros-eixos aparecem tumefeitos e engrossados, enquanto outros estāo atróficos ou desaparecem. As bainhas de mielina se reduzem, restando às vêzes uma borda delgada de mielina junto aos cilindros-eixos tumefeitos, rodeados por células de Schwann proliferadas e por fibras colágenas, formando característicos "bulbos de cebola". Dentro dos nervos se encontra uma substância mucosa, sendo a atrofia das bainhas de mielina seguida por depósito de gordura. O exame histo-patológico do ôlho mostra quadro típico de retinite pigmentar, com perda da porção periférica da camada granular externa e redução das demais camadas; os vasos aparecem rodeados por depósitos de pigmentos. Depósitos de gordura foram assinalados no figado, nos rins, nos testículos e no coração.

O emprêgo de dietas que não contenham fitol ou ácido fitânico tem provocado acentuada redução da concentração de ácido fitânico no sôro de alguns pacientes. Embora tenha havido melhora clínica subjetiva e objetiva da sintomatologia em um ou outro caso, é necessária maior experiência para uma avaliação mais completa. Não há dúvida, porém, de que os casos diagnosticados bioquìmicamente devem ser submetidos à dieta, bem como os indivíduos aparentemente normais e os irmãos dos pacientes que apresentem taxas elevadas de ácido fitânico.

\section{Moléstia de Wolman}

Doença familial transmitida com caráter autossômico recessivo, sendo caracterizada pelo acúmulo de triglicérides e colesterol em vários órgãos e por calcificação bilateral das adrenais. O início da doença se dá nas primeiras semanas de vida, com diarréia, vômitos e interrupção do desenvolvimento sômato-psíquico. Gradativamente a criança torna-se apática e, em pouco tempo, apresenta-se em completa deterioração clínica, sobrevindo a morte em 3 a 4 meses.

Os depósitos anormais ocorrem no baço, fígado, gânglios linfáticos, timo, intestino delgado, medula óssea, adrenais e sistema nervoso central, onde são observadas células esponjosas. Ambas as adrenais apresentam-se calcificadas. A moléstia é muito semelhante à de Niemann-Pick e é possível que os casos descritos e diagnósticados como sendo desta afecção e que eram acompanhados de calcificação adrenal, correspondam realmente à moléstia de Wolman. O mecanismo responsável pelos depósitos de triglicérides e colesterol e pela calcificação das adrenais é ainda desconhecido.

\section{Sindrome de Bassen-Kornzweig}

Descrita em $1950^{1}$ esta sindrome neuromuscular se assemelha clìnicamente à ataxia de Friedreich, acompanhada de retinite pigmentar e acantocitose. Jampel e Falls ${ }^{3}$ verificaram baixa concentração de colesterol no sôro 
de um paciente e Salt e col. ${ }^{6}$ observaram redução acentuada de betalipoproteina em outro paciente. Em 1963, Schwartz e col. ${ }^{7}$ estudaram do ponto de vista bioquímico um paciente que havia sido motivo de publicação por Kornzweig e Bassen em $1957^{4}$, verificando a existência do distúrbio complexo do metabolismo lipídico, traduzido por alteração da absorção de gorduras e ácidos gordurosos, deficiência de beta-lipoproteína no sôro e redução na concentração dos lípides totais, triglicérides, colesterol e de fosfolípides no sôro. A doença é transmitida com caráter autossômico recessivo.

Clinicamente, a moléstia se caracteriza por distúrbios neuromusculares, retinite pigmentar, esteatose e presença de hemácias anormais, denominadas acantócitos. Os sinais neurológicos mais freqüentes são ataxia, perda de sensibilidade proprioceptiva e arreflexia; menos vêzes observa-se perda da fôrça muscular, sinais piramidais, perda da sensibilidade superficial com distribuição periférica, oftalmoparesias. Alguns casos apresentam cifoescoliose acentuada.

\section{DISTURBIOS DO METABOLISMO DOS HIDRATOS DE CARBONO}

\section{Galactosemia}

Entidade genética, de caráter autossômico e transmitida recessivamente, que resulta da deficiência da enzima que transforma a galactose-1-fosfato em glicose-1-fosfato; nas crianças afetadas pela doença esta via está bloqueada, resultando aumento da galactose-1-fosfato que se acumula nos tecidos ${ }^{4}$.

As manifestações surgem ao ređor da segunda semana de vida, com ictericia, fenômenos gastrintestinais, perda de pêso, hepatosplenomegalia, letargia, hipotonia muscular e catarata; esta última que pode estar presente desde o nascimento, resulta da diminuição de trifosfato de adenosina no cristalino ${ }^{2}$. Se a moléstia não é diagnosticada, evolui para a cirrose hepática e deficiência mental, surgindo convulsōes e sinais neurológicos focais, ascite e hemorragia. A morte sobrevém nas primeiras semanas de vida se o tratamento não for instituído. Nos casos menos graves, a intolerância ao leite pode ser o único sintoma.

A galactose é um monossacáride resultante da hidrólise da lactose e, em condições normais, é transformada em galactose-1-fosfato que, por ação enzimática, passa a glicose-1-fosfato. O bloqueio desta última etapa determina acúmulo de galactose-1-fosfato nos tecidos, o que diminui o consumo de oxigênio pelas hemácias. A hiperaminoacidúria é secundária, decorrendo da ação da galactose-1-fosfato sôbre a célula renal. A hipoglicemia seria explicada pela resposta insulínica ao aumento da galactose-1-fosfato no sangue, à inibição da glicose-6-fosfatase ou à inibição da fosfoglicomutase.

O mecanismo responsável pela deficiência mental também não é conhecido. Poderia ser decorrente da hipoglicemia ou da alteração dos receptores da serotonina no sistema nervoso central, seja pela inibição dêsses receptores pela galactose-1fosfato aumentada, seja pela falta de inclusão de derivados da glicose nesses mesmos receptores. 
A doença será confirmada pelos dados de laboratório: (a) presença de substância redutora na urina, identificada mediante cromatografia; (b) proteinúria; (c) hiperaminoacidúria, que inclue principalmente os aminoácidos neutros de cadeia curta (glicina, alanina, serina e tirosina); $(d$ ) hipoglicemia; ( $e$ ) hipergalactosemia; $(f)$ alteração de taxa de galactose-1-fosfato nos eritrócitos; $(g$ ) diminuição da atividade da galactose-1-fosfato-uridil-transferase nos eritrócitos; $(h)$ alterações das funções hepáticas, com bilirrubinemia, elevação da fosfatase alcalina e aumento de tempo de protrombina.

Como tratamento, é obrigatória a exclusão de leite e substâncias que contenham lactose e galactose. Em substituição ao leite existem, em alguns países, preparados especiais. Em nosso meio, Nóbrega, Schmidt e Carvalho (J. Pediat. 30:89, 1965) sugeriram o uso da mamadeira de carne, com resultado satisfatório. A restrição dietética deve ser feita durante, pelo menos, 3 a 4 anos.

\section{Glicogenoses}

Moléstia de Pompe (glicogenose tipo II) - Descrita em $1932^{9}$, representa uma das formas raras do grupo de doenças de depósito de glicogênio. E devida a uma deficiência de maltase ácida ${ }^{5,6}$ e caracterizada por acúmulo exagerado de glicogênio, não apenas no fígado e rins, como acontece na doença de von Gierke, mas também nos músculos esqueléticos, coração, músculos lisos, glândulas endócrinas e sistema nervoso. Os sintomas iniciais são observados no período neonatal e progressivamente são agravados, sobrevindo a morte dentro do primeiro ano de vida.

O comprometimento cardíaco pode ser notado logo após o nascimento. A medida que outros órgãos são comprometidos, a sintomatologia torna-se mais complexa. A hepatomegalia é evidente. O comprometimento neuromuscular é traduzido por hipotonia acentuada; a cabeça não é sustentada, a criança não consegue manter-se na posição sentada, os músculos do pescoço são extremamente fracos; os reflexos profundos estão abolidos. Fasciculações são fàcilmente observadas na língua que, ulteriormente, fica imóvel, protruindo entre os lábios. A fôrça muscular é muito diminuida. Os nervos cranianos são freqüentemente comprometidos, particularmente $o$ facial e o hipoglosso ${ }^{8}$.

O exame anátomo-patológico mostra lesōes no coração, no fígado, nos rins, nos músculos esqueléticos, sendo as fibras e células impregnadas de material PAS positivo. O cérebro é, em geral, pálido e brilhante, mas o exame do córtex em diferentes niveis, mostra a substância branca e a substância cinzenta com aspecto normal. A medula pode apresentar diminuição da mielina. Os neurônios corticais aparecem aumentados de volume, com depósitos de glicogênio. O comprometimento dos astrócitos e oligodendroglia é discreto, podendo ser mais evidente na substância branca. No cerebelo, as células de Purkinje têm aspecto normal; as células da camada granular e as células da substâncias branca e dos núcleos denteados podem apresentar depósitos. Os neurônios das colunas anterior e posterior podem estar comprometidos, com grande distensāo e acumulo do glicogênio, chegando a um volume 2 ou 3 vêzes maior que o normal. Alterações semelhantes são encontradas nos núcleos dos nervos cranianos. Estudos bioquímicos têm demonstrado que 0 
teor de glícogênio é sempre mais elevado na substância branca que na cinzenta. Crome e col. ${ }^{1}$ encontraram diminuição de fosfolípides, colesterol e cerebrósides.

Curiosamente não têm sido assinaladas alterações do metabolismo dos hidratos de carbono nesses pacientes ${ }^{3}$. Raramente têm sido observadas glicosúria $^{11}$, acetonúria ${ }^{2}$ e respostas anormais à insulina ou adrenalina ${ }^{4}$, contrastando com a freqüente ocorrência de tais alterações em outras glicosúrias. O diagnóstico em vida tem sido firmado mediante biópsia muscular ou hepática. Os leucócitos dêsses pacientes apresentam baixa atividade de maltose ácida ${ }^{6}$; é importante notar, entretanto, que pessoas normais também podem apresentar deficiência dessa enzima.

Tentativas de tratamento foram feitas, em caráter experimental, com o uso de alfa-glucosidase; a melhora foi, no entanto, transitória, e a moléstia evoluiu para a morte antes do fim do primeiro ano de vida.

Moléstia de Mc Ardle (glicogenose tipo V) - Em 1951, Mc Ardle ${ }^{2}$ publicou o caso de um paciente de 30 anos que sempre apresentara intolerância aos exercícios físicos, pois o esfôrço prolongado de qualquer músculo provocava dor local, rigidez e fraqueza muscular. Os exames físico e neurológico eram normais. O repouso melhorava os sintomas. A esquemia provo. cada no antebraço resultava em encurtamento dos músculos flexores, que se mostravam elètricamente silenciosos e em estado de contratura fisiológica; a isquemia não provocava a elevação normal de ácido lático venoso. Mc Ardle sugeriu, então, a existência de um bloqueio no mecanismo responsável pela transformação do glicogênio em ácido lático.

Schmidt e col. ${ }^{7}$ e Pearson e col. ${ }^{3}$ demonstraram que havia ausência de fosforilase nos músculos esqueléticos e aumento do glicogênio muscular. Estudos histológicos de músculos demonstraram depósitos normais de glicogênio no sarcolema e em porções mais centrais das fibras; tais achados foram ulteriormente confirmados pela microscopia eletrônica 6,8 .

Desde 1951 foram publicados cêrca de 25 casos dessa doença ${ }^{1}$. Embora exista a queixa desde a infância, a maioria dos casos tem sido identificada na idade adulta. A doença tem sido observada com caráter familial em cêrca de $50 \%$ dos casos, sugerindo transmissão hereditária com caráter autossômico recessivo.

Moléstia de Tarui (glicogenose tipo VII) - Em 1965, Tarui e col. ${ }^{1}$ relataram os casos de 4 pacientes, dos quais 3 irmãos, que apresentavam manifestações clinicas semelhantes às da moléstia de Mc Ardle, incluindo fadiga fácil, cãimbras, mioglobinúria e incapacidade de produção do ácido lático após exercício muscular na vigência de isquemia. Demonstraram, bioquìmicamente, uma deficiência do fosfofrutoquinase, e acúmulo de glicogênio, glícose-6-fosfato e frutose-6-fosfato nos músculos. A avaliação da atividade de fosfofrutoquinase nos glóbulos sangüineos, mostrou valor normal nos leucócitos e reduzido nas hemácias. A doença parece ser transmitida com caráter autossômico recessivo. 
Moléstia de Thomson (glicogenose tipo VIII) - Thomson e col. ${ }^{1}$ descreveram, em 1963, outra forma de glicogenose. Tratava-se de um menino com 4 anos de idade que foi examinado por apresentar alteração de marcha pois caminhava apoiado nas pontas-dos-pé desde os dois anos e meio sem se queixar de cansaço, dor ou cãimbras musculares. A musculatura esquelética parecia, ao exame, mais fraca e menos desenvolvida que o normal; ambos os gastrocnêmios mostravam-se pseudohipertrofiados e duros, e havia encurtamento do tensão de Aquiles, com resultante deformação de ambos os tornozelos. A eletromiografia mostrou que os quadriceps e os gastrocnêmios apresentavam respostas de tipo miopático na contração voluntária contra resistência, com potenciais de baixa voltagem e de curta duração. Os exames bioquímicos mostraram deficiência de fosfoglicomutase e alterações parciais da glicólise.

\section{Intolerância hereditária à frutose}

Descrita em 1956 por Chambers e Pratt $^{1}$ a doença caracteriza-se pela presença de frutose na urina e hipoglicemia, com manifestações gastrintestinais e deficiência mental. E doença genética, transmitida com caráter autossômico recessivo ${ }^{4}$.

Os primeiros sintomas aparecem durante o primeiro ano de vida e, muitas vêzes, nas primeiras semanas. A sintomatologia inicial é inespecifica, com anorexia, náuseas e vômitos, geralmente desencadeada por alimentos que contenham frutose e sacarose. Podem associar-se sinais sugestivos de hipoglicemia. Existe retardo no desenvolvimento ponderal e estatural. O exame físico pode mostrar hepatomegalia sem esplenomegalia. Raramente é observada icterícia ${ }^{2}$. As perturbações digestivas podem ser graves desde o início, mas alguns casos evoluem mais favoràvelmente, com os vômitos surgindo apenas quando o paciente use alimentos que contenham frutose. O comprometimento mental parece depender da hipoglicemia ${ }^{3}$. As crianças afetadas apresentam acentuada resistência à cárie dentária.

A intolerância à frutose parece ser devida a um defeito de utilização dêsse açúcar, conseqüente a um bloqueio da enzima frutose-1-fosfato-aldolase na fase de transformação de frutose-1-fosfato em trioses.

O diagnóstico precoce é difícil diante da inespecificidade da sintomatologia clínica. Seria necessária a pesquisa de substâncias redutoras na urina de lactentes com sinais sugestivos de hipoglicemia ou com sinais digestivos e hepatomegalia. Uma vez constatada a presença dessas substâncias é necessária a sua identificação mediante cromatografia. Em geral, existem hipoglicemia, hipofosfatemia, albuminúria e hiperaminoacidúria associadas. A confirmação diagnóstica será feita pela prova de sobrecarga de frutose.

O tratamento consiste no uso de dieta sem frutose implicando na absten. ção de sacarose e insulina. Assim, açúcar de cana, açúcar de beterraba, mel, frutas, cenouras e diversos outros vegetais devem ser proibidos. 


\section{Mucopotissacaridoses (MPS)}

As mucopolissacaridoses constituem grupo de doenças metabólicas genèticamente determinadas, nas quais ocorre depósito anormal de polissacáridos ácidos em diversos órgãos, com conseqüentes distúrbios morfológicos e funcionais; o diagnóstico é baseado na comprovação de eliminação anormal de polissacárides ácidos pela urina. A classificação das mucopolissacaridoses ainda não está perfeitamente estabelecida e atualmente são reconhecidos 6 subgrupos, identificados por características genéticas, clínicas e bioquímicas.

O gargulismo (MPS 1; doença de Hurler; síndrome de Hurler; doença de Pfaundler-Hurler; doença de Hunter-Hurler; lipocondrodistrofia; disostose múltipla; condrodistrofia) é a primeira afeç̧ão em que foi comprovado distúrbio metabólico dos MPS, comprometendo o esqueleto e os tecidos moles. Embora o distúrbio do metabolismo já esteja presente ao nascimento, a maioria dos sintomas surge na primeira e segunda infâncias. A doença é hereditária, transmitindo-se por gene autossômico recessivo, e caracteriza-se por opacificação da córnea, hepatosplenomegalia, deficiência mental, alterações esqueléticas, fácies grotesca e nanismo. Hunter fez a primeira descrição da moléstia em 1917, embora êsse caso seja hoje considerado como uma das "formas frustas" da doença. A forma completa da doença foi descrita por Gertrude Hurler em 1919.

O distúrbio metabólico básico resulta na deposição de material anormal intracelular, provàvelmente MPS ácidos. Na urina são encontrados o ácido condroitin-sulfúrico $B$ e o sulfato de heparitina, em taxas anormais.

Desde 1942 Jervis i assinalou aumento de gangliosideos nas células nervosas nos casos de gargulismo. Foi verificado também que tanto as células viscerais como conjuntivas apresentam depósito de mucopolissacarideos que, eletroforética e cromatogràficamente, correspondem ao ácido condroitinsulfúrico. No cérebro, além dos gangliosídeos encontrados nas células nervosas, existe acúmulo de mucopolissacarídeos nas células adventicais. Uzzman (citado por Diezel *), analisando o material colhido em 4 casos de gargulismo, encontrou duas substancias de depósito: um polissacarídeo composto de glicose, galactose, hexosamina e sulfatos que, ao azul de toluidina, apresentava metacromasia, e um glicolipide contendo ácidos graxos, esfingosina, ácido neuramínico, ácido hexurônico, hexosamina, glicose e galactose.

Os aspecto dos pacientes é tipico, podendo ser reconhecidos à primeira vista, como se pertencessem a uma mesma família. Ainda que possam ser considerados como de aspecto normal ao nascerem, gradativamente se vão alterando no desenvolvimento físico, que se torna francamente patológico ao redor dos 3-4 anos de idade. $O$ paciente tem as características de anão; o crânio é volumoso, as bossas frontais são proeminentes. A face é larga, os traços fisionômicos são grosseiros. As arcadas superciliares são grossas e as rimas palpebrais amplas; existe hipertelorismo e, freqüentemente, opacidade corneana. As orelhas são grandes e de baixa implantação. O nariz é achatado na base, com as narinas amplas. A boca é larga, os lábios grossos e evertidos; a língua, fissurada e grande, mantem-se protruida entre os lábios semi-abertos. Os dentes são malformados, pequenos, separados entre si, de 
coloração amarelada. O pálato é ogival. A voz é gutural. A pele é frouxa, recoberta de pêlos densos e pode apresentar manchas escuras na região dorsal e nas regiōes glúteas (Lefèvre e col. ${ }^{6}$ ). O pescoço é curto, o tronco maciço. $\mathrm{O}$ abdome é volumoso; a palpação e percussão revelam hepatosplenomegalia. Ao fim do primeiro ano aparece cifose dorsolombar, que se acentua progressivamente. Os membros são deformados; os braços são curtos, as mãos volumosas e os dedos grossos; os membros inferiores são finos, com joelhos grossos e valgos.

Há deficiência mental, em cêrca de $80 \%$ dos casos. Todavia, os pacientes demonstram certa afetividade para as pessoas com quem convivem. A deficiência pode se agravar com o crescimento, chegando à idiotia.

$\mathrm{O}$ exame radiológico mostra discretas anormalidades durante os primeiros meses de vida, mas após um ou dois anos as alterações ósseas são múltiplas e simétricas. O crânio é volumoso, com aumento de todos os diâmetros. O osso frontal é bastante desenvolvido e espessado. A sutura coronária pode apresentar-se em diástase e a fontanela fecha-se tardiamente. Os ossos da base do crânio, com retardo no desenvolvimento, são hipoplásicos em comparação com os da abóbada. No perfil, a base é achatada; a sela turca é deformada, com apófises clinóides irregulares. O maciço facial, em conjunto, é hipertrófico; longo no sentido transversal, curto no sentido sagital. A coluna vertebral apresenta cifose dorso-lombar, devida à hipoplasia dos corpos das últimas vértebras dorsais e primeiras lombares. Os ossos longos sofrem curvaturas e desvios da diáfise. Os metacarpianos e falanges são curtos, alargados e mais grossos na porção correspondente à articulação metacarpo-falangiana e afilados na extremidade oposta. $\mathrm{Na}$ bacia, os ramos ísquiopúbicos são pouco desenvolvidos e apresentam atraso de soldadura. As alterações dos membros inferiores são semelhantes às dos superiores, embora em menor intensidade.

Cêrca de um terço dos casos de gargulismo correspondem à forma completa da doença. Os outros dois terços não apresentam algumas das manifestações clínicas, constituindo formas incompletas ou mesmo frustas.

As leptomeninges podem conter depósitos de lípides e macrófagos, e se apresentam fibrosadas. Os neurônios apresentam volume aumentado. O material depositado no citoplasma cora-se em laranja pelo escarlate $R$, em prêto-esverdeado pelo sudan negro e é fortemente positivo para o PAS e tionina de Feyrter. Após tratamento com solventes para lipides, o material corado pelo PAS é removido, permanecendo um residuo insolúvel, corado pelo escarlate ${ }^{1}$. No caso de Sena e Caymmi "o material acumulado nas células dos vários órgãos assumia aspectos variáveis, sendo encontrados todos os graus intermediários entre células com citoplasma PAS positivo e outras com citoplasma espumoso e vazio. Isto sugere graus variáveis de solubilidade da substância mucopolissacáride. Dawson já havia observado diferenças físico-químicas entre o material depositado nas células nervosas e em outros tecidos".

A distensão das células nervosas no córtex cerebral pode ser discreta nos núcleos pontinos e intensa no tálamo; os neurônios do putamen podem assumir grande volume, enquanto no núcleo caudado apresentam discreto aumento. A destruiçăo neuronal é infreqüente. Na substância branca podem ser encontradas áreas de gliose, embora as alterações da mielina sejam discretas. Achado quase constante é a 
presença de espaços perivasculares dilatados no centro semi-oval, ocupados por reticulos de fibrilas colágenas, derivadas da adventícia dos vasos. No cerebelo, as células de Purkinje apresentam lipidose moderada 5. As células hepáticas contém grandes vacúolos que, em geral, aparecem vazios quando o material é flxado em formol ou álcool; em cortes de congelação, aparece material que se cora pelos métodos para lipides e pelo PAS ${ }^{2}$. No baço, o comprometimento das células que revestem os sinusóldes é idêntico. As alteraçōes ósseas são variáveis; em alguns casos não têm sido observadas modificações microscópicas e, ocasionalmente, as células cartilaginosas mostram inclusões intensas e vacúolos ${ }^{2}$. A opacidade da córnea é devida à deposição de material nas células de membrana de Bơwman.

O diagnóstico deve se apoiar em dados laboratoriais. O teste de DorfmanSteiness permite a verificação do aumento da excreção de mucopolissacáride pela urina. A determinação qualitativa dos mucopolissacárides mostra aumento da eliminação de ácido condroitin-sulfúrico $B$ e de sulfato de heparitina. O estudo hematológico poderá revelar as granulações de Alder nos leucócitos e as anomalias de Gasser, consistindo na vacuolonização do citoplasma dos linfócitos.

A moléstia de Hunter (MPS-2) tem características semelhantes às do gargulismo, embora de modo geral seja menos grave, de evolução mais lenta, e de transmissão genética ligada ao sexo. As alterações esqueléticas são menos importantes, a opacidade corneana é inconstante e tardia; alterações retinianas e surdez são mais freqüentes e a cardiopatia é constante. A decadência mental é de instalação mais lenta e a sobrevivência é maior. Na urina são identificadas as mesmas substâncias encontradas no gargulismo.

Daneo e Bearn demonstraram que as culturas in vitro de fibroblastos dos pacientes contém quantidades anormais de MPS que se coram metacromàticamente pelo azul de toluidina. A prova sempre foi positiva nas mães de pacientes com a doença de Hunter.

A moléstia de Sanfilippo (MPS-3), também chamada de oligofrenia polidistrófica, é de aparecimento mais tardio, sendo transmitida com caráter autossômico recessivo. O comprometimento esquelético é menos intenso; nos primeiros anos a estatura pode ser normal e, em geral, só no adulto se nota o déficit da altura. A pele é seca, áspera, hipertricótica; o crânio é volumoso, com bossas frontais salientes, rebordo orbitário acentuado, supercilios espêssos. Não há opacidade da córnea. Há hẹatomegalia. O sintoma predominante é a deficiência mental que se instala progressivamente, com involução de funções já adquiridas, perda da linguagem, distúrbios de comportamento e, de modo gradual, evolução para a idiotia.

O craniograma mostra espessamento das tábuas ósseas e da base; o exame radiológico da coluna vertebral evidência vértebras dorsais e lombares deformadas, ovóides, com esbôço de esporōes em anzol. O exame de sangue mostra as células de Gasser; na medula óssea aparecem as células de Buhot e histiócitos com granulações basófilas. Na urina há eliminação excessiva de sulfato de heparitina. 
A moléstia de Mórquio (MPS-4), conhecida também como osteocondrodistrofia, é caracterizada pela eliminação de queratossulfato em altas doses na urina, sendo transmitida com caráter autossômico recessivo. Clìnicamente há nanismo; o pescoço é curto e a cabeça, volumosa, aparece como que afundada entre as espáduas, em hiperextensão e com protrusão do maciço inferior da face. Podem ocorrer fusão das vértebras cervicais e platibasia. $O$ tórax é curto e largo e o diâmetro ântero-posterior é aumentado, com protrusão do esterno. A coluna vertebral é deformada por cifoescoliose. O abdome é saliente. Os membros superiores, extremamente longos, alcançam o nível dos joelhos e o rádio e cúbito apresentam alteraçōes das epífises. A mão e os dedos são finos e longos. As condições mentais são normais ou discretamente diminuídas. Ocasionalmente há hepatosplenomegalia. A moléstia se instala entre os 18 meses e 2 anos de idade. As granulações de Alder são inconstantes no sangue periférico.

A moléstia de Scheie (MPS-5), também identificada como Hurler tardio, é caracterizada por transmissão com caráter autossômico recessivo e pela eliminação exagerada de ácido condroitin-sulfúrico $B$ na urina. Clìnicamente, o sinal mais importante é a opacidade da córnea, que pode estar associada a retinite pigmentosa. O desenvolvimento estatural e ponderal é normal. As alterações ósseas e faciais são mínimas ou inexistentes. A hepatosplenomegalia está presente na grande maioria dos casos. A hipertricose é evidente. Em alguns casos foi relatada a síndrome do túnel do carpo.

A moléstia de Maroteaux e Lamy (MPS-6), também denominada nanismo polidistrófico, é muito rara, sendo transmitida com caráter autossômico recessivo e caracterizada por aumento da excreção do ácido condroitin-sulfúrico B. Inicia-se ao redor dos 2 anos e se traduz por quadro predominantemente ósseo; existe retardo no desenvolvimento da estatura, devido a alterações do tronco e membros. Há cifoescoliose lombar, protrusão do esterno, genu valgum. A hepatosplenomegalia, opacificação da córnea e surdez de tipo misto estão sempre presentes. O exame radiológico mostra irregularidade das epífises e metáfises, platibasia, achatamento das vértebras. $O$ estado mental é bom, embora possa haver discreta deficiência em alguns pacientes. Granulações metacromáticas são identificadas nas células mononucleadas do sangue periférico.

\section{DISTÚRBIOS DO METABOLISMO DAS METAL-PROTEINAS}

\section{Degeneracão hepatolenticular}

Doença hereditária, transmitida por um gene recessivo, e devida a um distúrbio do metabolismo da ceruloplasmina, com conseqüente redução de seus valores no sôro, aumento das taxas de cobre em vários tecidos e órgãos, e eliminação anormal de cobre pela urina. E caracterizada clìnicamente por sintomas extrapiramidais e degeneração hepática. 
A história da degeneração hépatolenticular começou com os casos de "pseudoeselerose" relatados por Westphall (1883) e por Strumpell (1898). Em 1902, Kayser fez a descrição de um anel amarelo-esverdeado ou marron e supostamente congénito, no bordo da córnea de um paciente com diagnóstico de "esclerose múltípla". No ano seguinte, Fleischer observou um caso de "pseudoesclerose" o outro de "esclerose múltipla" com anéis semelhantes, sugerindo que a manifestação fosse de típo adquirido. Em 1911, Voelsch apresentou o exame patológico de um caso de "pseudoesclerose", chamando a atenção para a cirrose nodular atrófica do figado. Em 1912, Kinnier Wilson descreveu as manifestaçôes clínicas e os achados patológicos, salientando a incidência familial da doença que chamou de degeneração lenticular progressiva. Em 1920, Spielmeyer concluiu que, do ponto de vista patológico, a "pseudoesclerose" de Westphall e Strumpell e a moléstia de Wilson representavam duas formas de uma mesma doença que Hall", em 1921, denominou degeneração hépato-lenticular.

Na maioria dos casos a moléstia se inicia entre os 11 e os 25 anos, sendo sua freqüência ligeiramente maior no sexo masculino que no feminino. Os sinais e sintomas são dependentes das lesōes hepáticas e cerebrais. Em geral, a cirrose é assintomática, mas ictericia e ascite podem ocorrer em qualquer fase da moléstia; sintomas hepáticos podem, mesmo, precerder de vários anos as manifestações neurológicas.

A sintomatologia neurológica é variada. Os sintomas extrapiramidais são predominantes, mas sinais cerebelares podem surgir. Tremor e rigidez são os sinais mais precoces. O tremor pode ser de tipo intencional ou de tipo alternante. Freqüentemente observa-se um tremor bizarro, localizado nos membros superiores, descrito como "bater-de-asas"; o tremor tende a desaparecer quando os membros estão em repouso e aparecem quando os membros são estendidos. Os movimentos podem estar confinados aos músculos do punho mas, em boa parte dos casos, os membros são elevados e abaixados.

Rigidez e espasmos musculares são freqüentes; a rigidez pode ser do tipo parkinsoniano, comprometendo tôda a musculatura. Movimentos distônicos podem ocasionalmente ser observados. A rigidez dos músculos laríngeos e faríngeos pode ser responsável por disartria e disfagia. Queda da mandíbula e salivação abundante são achados comuns. Alterações mentais e crises convulsivas podem aparecer. $\mathrm{O}$ anel de Kayser-Fleischer, de côr amarelo-esverdeada, marron ou cinza-esverdeada está presente em cêrca de $60 \%$ dos casos. A freqüência será provàvelmente maior se os pacientes forem todos examinados com lâmpada de fenda.

As alterações patológicas no sistema nervoso são difusas envolvendo particularmente os núcleos da base e cerebelo. Macroscòpicamente os núcleos da base estão atrofiados, necróticos ou, ocasionalmente, císticos. As cavidades ventriculares podem estar aumentadas. Hả contraste entre o tálamo, relativamente bem conservado, e o putamen e núcleo caudado, atrofiados. $O$ córtex cerebral pode apresentar atrofia, particularmente de localização frontal e parietal. As alterações microscópicas são representadas por degeneração neuronal que predomina nas células maiores. A resposta glial não aparece ou então é discreta, havendo aumento dos espaços perivasculares, com degeneração hialina e calcificação dos vasos. Spielmeyer registrou o encontro de células gliais de Alzheimer, espalhadas no sistema nervoso, principalmente no núcleo lenticular, na regiāo fronto-parietal e no cerebelo. 
As alteraçōes hepáticas são as de una cirrose nodular; as alteraçóes microscópicas são variadas, com focos de necrose, de degeneração ou de regeneração, separados por tecido conjuntivo. As alterações encontradas no baço são geralmente secundárias à congestão venosa provocada pela cirrose hepática. Na córnea, o anel de Kayser-Fleisher é formado por finos grânulos amarelo-ouro, depositados na membrana de Descemet.

O defeito primário seria a diminuição da ceruloplasmina no sangue, por transmissão hereditária de tipo recessivo autossômico ${ }^{1}{ }^{17}$. Normalmente, $90 \%$ do cobre sérico está ligado à ceruloplasmina, uma proteína da fração eletroforética alfa-2. Para Uzman e col. ${ }^{20}$ haveria um defeito de metabolismo protêico żeral provocado pela deficiência de carboxipeptidase tissular com formação de proteínas ou resíduos polipetídicos com grande afinidade pelo cobre. Seu metabolismo incompleto provocaria a excreção urinária de peptídeos cúpricos que competiriam ou bloqueariam a reabsorção tubular de aminoácidos e outras substâncias. Assim, a deficiência de ceruloplasmina seria acidental, sendo a fixação de grandes quantidades de cobre r.os tecidos causada pela concentração peptídica anormal e independente do estado físico-químico do cobre no plasma. Em apôio a esta teoria, foi constatada maior afinidade para o cobre pelo tecido hepático de pacientes com degeneração hepatolenticular que em indivduos normais ou com cirrose de causas comuns. Contido, foi provado não haver proteínas anormais no cérebro e no figado dos pacientes ${ }^{13}$, ${ }^{16}$. A ligacão do cobre se faz com proteinas cerebrais normais que, em individuos sadios, nāo se ligam ao metal.

o conceito da doença de Wilson ser exclusivamente devida a um defeito de sintese de ceruloplasmina com a subsequente deposição tissular do cobre "livre" é, no entanto, abalado pelo fato de haver pacientes com niveis de ceruloplasmina normais ou próximas da normalidade ${ }^{14},{ }^{19}$. Por outro lado, há pacientes com hipoceruloplasminemia sem degeneração hépatolenticular ${ }^{6}$.

A administração de cobre radioativo por via oral e por via endovenosa mostra sua associação à fração ceruloplasminica das proteinas séricas. Embora a captação do cobre marcado pelo fígado de pacientes com doença de Wilson seja usualmente menor que no fígado de indivíduos normais, o não reaparecimento do metal na circulação reflete o aumento da fixação hepática. Parece razoável atribuir tai fenómeno à incapacidade de sintese hepática da ceruloplasmina.

O'Reilly ${ }^{15}$ notou que a fixaçāo de cobre marcado nos glóbulos vermelhos de doentes é mais demorada, indicando alteração de incorporação pela eritrocupreina, proteína essa que se encontra em niveis normais na moléstia de Willson. Em experiência no rato, Hermann e Kun ${ }^{11}$ demonstraram o papel inibidor do hormônio de crescimento sôbre o acúmulo de cobre nas mitocôndrias hepáticas, fato êsse interessante pela conhecida contribuição dêsse hormônio na sintese protêica. Não se pode descartar definitivamente a teoria de haver proteinas anormais até que sejam caracterizadas completamente as propriedades físico-químicas das moléculas de ceruloplasmina. Canelas e col. ${ }^{4}$ constataram balanço metabólico de enxofre positivo em dois pacientes com degeneração hépatolenticular, negativando-se com a administração de D-penicilamina.

O diagnóstico laboratorial baseia-se fundamentalmente na diminuição de ceruloplasmina abaixo de $20 \mathrm{mg} / 100 \mathrm{ml}$ e no acúmulo de cobre no tecido hepático, obtido por biópsia. O'Reilly ${ }^{15}$ resumiu as alterações do metabolismo do cobre e os transtornos renais da seguinte forma: diminuição do cobre sérico total; aumento do cobre "livre" ou de conjugação lábil; diminuição da ceruloplasmina no sôro; aumento da absorção intestinal do cobre e/ou diminuição da excreção intestinal; aumento da excreção urinária do cobre; aumento de cobre nos tecidos (cérebro, fígado, córnea e rins); lentificação da depuração do cobre plasmático pelo fígado e lentificação de incorporação de 
cobre à ceruloplasmina; aminoacidúria generalizada; diminuição do fluxo plasmático renal; diminuição da filtração glomerular; diminuição da reabsorção tubular máxima de p-aminohipúrico; redução da reabsorção máxima de glicose; aumento do ácido úrico urinário com redução do ácido úrico sérico; aumento do fosfato urinário com diminuição do fosfato inorgânico sérico; aumento do cálcio urinário; tendência à perda de bicarbonato; por vêzes diminuição da capacidade de concentração e, ocasionalmente, albuminúria e glicosúria. Canelas e col. ${ }^{5}$ salientaram a ausência de prealbumina e os baixos níveis de globulina alfa-1 e alfa-2 no proteinograma do líquido cefalorraqueano. Observaram ainda redução dos valores de fósforo e magnésio no sôro sangüineo.

O tratamento tem dois objetivos: diminuir a ingestão e a absorção do cobre e provocar a excreção do metal depositado nos tecidos.

O primeiro objetivo é conseguido com uma dieta contendo menos que $2 \mathrm{mg}$ de cobre por dia. A dieta vegetariana provoca diminuição acentuada no balanço cúprico positivo. $O$ aumento do cobre nas fezes sugere a ligação do metal a algum componente não absorvido ${ }^{3}$. Água distilada ou demineralizada deve ser utilizada nos locais em que o líquido contenha mais de 0,1 mg de cobre por litro. Foram feitas diversas tentativas de fixar o cobre proveniente da dieta. Tem sido usada uma forma comercial de sulfato de potássio, consistindo principalmente numa mistura de polissulfetos de potássio e de tiossulfato de potássio, à razão de $40 \mathrm{mg}$ às refeições.

Resinas de trocas cationicas como a carbacrilamina foram empregadas por Goldstein e col. ${ }^{8}$ com bons resultados. O'Reilly ${ }^{15}$ utilizou um agente quelante, o ácido dietilene-triamina-pentacético, com grande afinidade para o cobre não absorvido pelo trato gastrointestinal, com resultados encorajadores.

A excreção do cobre fixado nos tecidos é conseguida com o uso de agentes quelantes. O BAL (dimercaprol) foi introduzido na terapêtica da doença, em 1948, por Cumings. A medicação de escolha surgiu em 1956, quando Walshe apresentou seus primeiros resultados com a D-penicilamina. Estudos "in vitro" mostram que um átomo de cobre se combina com duas moléculas de penicilamina indicando que uma grama do produto deveria provocar a excreção de $200 \mathrm{mg}$ de cobre. Na prática a quantidade excretada é de cêrca de $11 \%$ dêsse valor. Hill e Walshe ${ }^{12}$ aventaram que os agentes quelantes tiólicos, como a penicilamina, podem agir tanto por sua capacidade em suprir os grupamentos sulfidrilas para o metabolismo intermediário, como pela mobilização do cobre em excesso, que inibiu e se combinou com agrupamentos sulfidrilas em enzimas do ciclo de Krebs. $O$ versene (EDTA) deu bons resultados nos doentes de Hall e Neale ${ }^{10}$. Sunderman e col. ${ }^{25}$ tiveram excelentes resultados com o dietilditiocarbamato. As tentativas de administração de ceruloplasmina purificada ${ }^{2}$ e de estrógenos para aumentar a produção endógena de ceruloplasmina ${ }^{7}$ falharam.

A insuficiência hepática deverá ser tratada sintomàticamente. Quanto às hipercinesias os melhores resultados foram obtidos com o Diazepam ${ }^{15}$. 
$R$ E F E R E C I A S

\section{Fenilcetonúria}

1. ALVORD, E. C.; STEVENSON, L. D.; VOGEL, F. L. \& ENGLE, R. L. - Neuropathological findings in phenyl-pyruvic oligophrenia. J. Neuropath. Exper. Neurol. 9:298, 1950.

2. ARMSTRONG, M. D. \& ROBINSON, K. S. - On the excretion of indole derivatives in phenylketonuria. Arch. Biochem. 52:287, 1954.

3. ARMSTRONG, M. D. \& SHAW, K. N. F. - Studies on phenylketonuria; the metabolism of alpha-tyrosine. J. Biol. Chem. 213:605, 1955.

4. ARMSTRONG, M. D. \& TYLER, F. H. - Studies on phenylketonuria; restricted phenylalanine intake in phenylketonuria. J. Clin. Invest. 34:565, 1955.

5. BECHAR, M.; BORNSTEIN, B.; ELIAN, M. \& SANDBANK, U. - Phenylketonuria presenting an intermittent progressive course. J. Neurol. Neurosurg. Psychiat. 28:165, 1965.

6. BENDA, C. E. - Developmental Disorders of Mentation and Cerebral Palsies. Grune \& Stratton, New York, 1952, pág. 451.

7. BICKEL, H.; BOSCOTT, R. J. \& GERRARD, J. - Observations on the biochemical error in phenylketonuria and its dietary control. In "Biochemistry of the Developing Nervous System", edit, por H. Waelsch, Academic Press, New York, 1955.

8. BICKEL, H.; GERRARD, J. \& HICKMANS, E. M. - Influence of phenylalanine intake on the chemistry and behaviour of a phenylketonuric child. Acta paediat. 43:64, 1954.

9. BROWN, D. M.; ARMSTRONG, M. D. \& SMITH, E. L. - Studies of phenylketonuria; serum proteins in phenylketonuria. Soc. Exper. Biol. \& Med. 89:367, 1955.

10. BRUGGER, C. - Die Ausscheidung von Phenylbrenztraubensaure im Urin von Schwaschsinningen. Schweiz Arch. Neurol. u Psychiat. 49:62, 1942.

11. CENTERWALL, W. R.; CENTERWALL, S. A.; ACOSTA, P. B.; CHINNOCK, R. F.; ARMN, V. \& MANN, L. B. - Phenylketonuria; dietary management of infants and young children. J. Pediat. 59:93, 1961.

12. CORSELLIS, J. A. - The pathological report of a case of phenylpyruvic oligophrenia. J. Neurol. Neurosurg. Psychiat. 16:139, 1953.

13. COWIE, V. C. - Phenylpyruvic oligophrenia. J. Ment. Sc. 97:505, 1951.

14. CROME, L. \& PARE, C. M. B. - Phenylketonuria. J. Ment. Sc. 106:862, 1960.

15. CROME, L.; TYMMS, V. \& WOLLF, L. I. - A chemical investigation of the defects of myelination in phenylketonuria. J. Neurol. Neurosurg. Psychiat. 25:143, 1962.

16. DAVISON, A. N. \& SANDLER, M. - Inhibition of 5-hydroxy-tryptophan decarboxilase by phenylalanine metabolites. Nature 181:186, 1958.

17. DIAMENT, A. \& LEFEVRE, A. B. - Fenilketonuria; estudo clínico e mediante biópsia cerebral. Arq. Neuro-Psiquiat. (Sāo Paulo) 25:1, 1967.

18. DRUMMOND, K. N.; MICHAEL, A. F. \& GOOD, R. A. - Tryptophan metabolism in a patient with phenylketonuria and scleroderma. Canad. Med. Ass. J. 94: 834, 1966.

19. ESPERON, L. C. - Fenilcetonúria; apresentação de três casos na raça negra. Pediat. prát. 37:39, 1966.

20. FERREIRA-FERNANDES, J. - Oligofrenia fenilpirúvica em melanodermia. Brasil méd. 64:225, 1950.

21. FOIS, A.; ROSENBERG, C. \& GIBBS, F. A. - The electroencephalogram in phenylpyruvic oligophrenia. Electroencephal. clin. Neurophysiol. 7:569, 1955.

22. GIBBS, F. A. \& GIBBS, E. L. - Atlas of Electroencephalography. AddisonWesley, Cambrige, 1941. 
23. GUTHRIE, R. \& SUSI, A. - A simple phenylalanine method for detecting phenylketonuria in large populations of newborn infants. Pediatrics 32:338, 1963.

24. JERvis, G. A. - Phenylpyruvic oligophrenia. Res. Nerv. Ment. Dis. Proc. 33:259, 1954.

25. JERVIS, G. A.; BLOCK, R. J.; BOLLING, D. \& KANZE, E. - Chemical and metabolic studies on phenylalanine. J. Biol. Chem. 134:105, 1940.

26. LA DU, B. \& MICHAEL, P. J. - An enzimatic spectophotometric method for determination of phenylalanine in blood. J. Lab. Clin. Med. 55:491, 1966.

27. LOW, N. L.; BOSMA, J. F. \& ARMSTRONG, M. D. - Studies on phenylketonuria; EEG studies. Arch. Neurol. Psychiat. 77:359, 1957.

28. Mac CREMAN, N. W. \& ROBINS, E. - Fluorimetric method for the determination of phenylalanine in serum. J. Lab. Clin. Med. 59:885, 1962.

29. MALAMUD, N. - Neuropathology of phenylketonuria. J. Neuropath. Exper. Neurol. 25:254, 1966.

30. MAUTNER, H. \& QUINN, K. V. - Phenylpyruvic oligophrenia. Ann. Paediat. 172:1, 1949.

31. McKEAN, C. M.; SCHAMBERG, S. M. \& GIORMAN, N. J. - A mechanism of the indole defect in experimental phenylcetonuria. Science 137:604, 1962.

32: NOBREGA, F. J.; JORGE, N.; SCHMIDT, B. J.; MOREIRA, M. H. \& CARVALHO, A. A. - Apresentação de dois casos de fenilcetonúria. Pediat. prát. $36: 97,1965$.

33. PENROSE, L. S. - Two cases of phenylpyruvic amentia. Lancet 1:23, 1935.

34. POSER, C. M. \& van BOGAERT, L. - Neuropathological observations in phenyIketonuria. Brain 82:1, 1959.

35. SCHOLZ, W. - Contribution a l'anatomie pathologique du système nerveux central dans l'oligophrenie phenylpyruvique. Encephale 46:668, 1957.

36. STADLER, V. H. - The electroencephalogram in phenylketonuria. Ann Paediat. $197: 429,1961$.

37. WATSON, C. W.; NIGAM, M. P. \& PAINE, R. S. - Electroencephalographic abnormalities in phenylpyruvic oligophrenie. Neurology 18:203, 1966.

38. WOOLF, L. I.; GRIFFITHS, R. \& MONCRIEFF, A. - Treatment of phenylketonuria with diet low in phenylalanine. Brit. M. J. 1:57, 1955.

39. WOOLF, L. I. \& VULLIAMY, D. G. - Phenylketonuria with a study upon it with glutamic acid. Arch. Dis. Childhood 26:487, 1951.

40. YARBRO, M. \& ANDERSON, J. A. - Tryptophan metabolism in phenylketonuria. J. Pediat. 68:895, 1966.

\section{Moléstia de Hartnup}

1. BARON, D. N.; DENT, C. E.; HARRIS, H.; HART, E. W. \& JEPSON, J. B. Hereditary pellagra-like skin rash with temporary cerebellar ataxia, constant renal aminoaciduria, and other bizarre biochemical features. Lancet 2:421, 1956.

2. HENDERSON, W. - A case of Hartnup disease. Arch. Dis. Childhood 33:114, 1958.

3. JEPSON, J. B. - Hartnup disease. In The Metabolic Basis of Inherited Disease, edit. por J. B. Stanbury, J. B. Wyngaarden \& D. S. Frederickson, 2. ed.. Mac Graw-Hill, New York, 1966, pág. 1283.

4. LOPEZ, F.; VELEZ, H. \& TORO, G. - Hartnup disease in two Colombian siblings. Neurology 19:71, 1969.

5. MILNE, M. D.; CRAWFORD, M. D.; GIRAO, G. B. \& LOUGHRIDGE, L. W. The metabolic disorder in Hartnup disease. Quart. J. Med. 29:407, 1960.

6. SCRIVER, C. R. - Hartnup disease; a genetic modification of intestinal and renal transport of certain neutral alpha-amine acids. New England J. Med. $273: 530,1965$. 


\section{Moléstia da urina com odor de xarope de bôrdo}

1. BUCKUP, H. T.; STEIN, M. L.; CRESPIN, J. \& SCHMIDT, B. - Hiperaminoacidúria com odor de xarope de bôrdo. Pediat. prát. (São Paulo) 34:361, 1963.

2. COCHRANE, W. A.; PAYNE, W. W.; SIMPKISS, M. J. \& WOOLF, L. I. Familial hypoglycemia precipitated by aminoacids. J. Clin. Invest. 35:411, 1956.

3. DANCIS, J.; HUTZLER, J. \& LEVITZ, M. - The diagnosis of maple syrup urine disease by the in vitro study of the peripheral leukocyte. Pediatrics $32: 234,1963$.

4. DANCIS, J.; JANSEN, V.; HUTZLER, J. \& LEVITZ, M. - The metabolism of leucine in tissue culture of skin fibroblasts of maple-syrup-urine disease. Biochem. Biophys. Acta 77:523, 1963.

5. HOOFT, C.; TIMMERMANS, S.; van WERVEBE, S.; HANWERE, R.; ROELS, H. \& EECKEN, H. V. - La maladie du siroup d'erable. Ann. Pediat. (Paris) $13: 83,1966$.

6. MACKENZIE, D. Y. \& WOOLF, L. I. - Maple syrup urine disease; an inborn error in the metabolism of valine, leucine and isoleucine associated with gross mental deficiency. Brit. Med. J. 1:30, 1959.

7. MENKES, J. H. - Maple syrup urine disease; isolation and identification of organic acids in the urine. Pediatrics 23:348, 1959.

8. MENKES, J. H.; HURST, P. L. \& CRAIG, J. M. - A new syndrome: progressive familial cerebral dysfunction with an unusual urinary substance. Pediatrics 14:462, 1954.

9. SILBERMAN, J.; DANCIS, J. \& FEIGIN, I. - Neuropathological observations in maple syrup urine disease. Arch. Neurol. 5:351, 1961.

10. SNYDERMAN, S. E.; NORTON, P. M.; ROITMAN, E. \& HOLT, Jr., L. E. Maple syrup urine disease, with particular reference to dietotherapy. Pediatrics 34:454, 1964.

11. TASHIAN, R. E. - Inhibition of brain glutamic decarboxylase by phenylalanine, leucine and valline derivatives; a suggestion concerning the neurological derect in phenylketonuria and branched chain ketonuria. Metabolism 10:393, 1961.

12. WESTALL, R. G.; DANCIS, J. \& MILlER, S. - Maple sugar urine disease; a new molecular disease. Amer. J. Dis. Child. 94:571, 1957.

\section{Sindrome de Lowe}

1. CHUTORIAN, A. \& ROWLAND, L. P. - Lowe's syndrome. Neurology (Minneapolis) $16: 115,1966$.

2. HABIB, R.; BARGETON, E.; BRISSAUD, H. E.; RAYMAND, J. \& LE BALL, J. E. - Constatations anatomiques chez un enfant atteint d'un syndrome de Lowe. Arch. franc. Pédiat. 19:945, 1962.

3. HOOFT, C.; VALCKE, R.; HERPOL ,J.; van BOGAERT, L. \& GUAZZI, G. C. Neurology and neuropathology of Lowe's syndrome. J. Neurol. Sc. 3:353, 1966.

4. ILLIG, V. R.; DUMERMUTH, G. \& PRADER, A. - Das oculo-cerebro-renale syndrom (Lowe). Helv. paediat. Acta 18:173, 1963.

5. LAMY, M.; FREZAL, J.; REY, J. \& LARSEN, C. - Etude metabolique du syndrome de Lowe. Rev. franc. Etud. clin. \& biol. 7:27, 1962.

6. LOWE, C. U.; TERRY, M. \& MacLACHLAN, E. A. - Organic aciduria, decreased renal ammonia production, hydrophthalmos and mental retardation. Amer. $J$. Dis. Child. 83:164, 1952.

7. SCHOEN, E. J. \& YOUNG, G. - Lowe's syndrome; abnormalities in renal tubular function in combination with other congenital defects. Amer. J. Mer!. $27: 781,1959$. 
8. SCHWARTZ, R.; HALL, P. W. \& GABUZDA, Jr., G. J. - Metabolism of ornithine and other amino acids in the cerebro-oculo-renal syndrome. Amer. $J$. Med. 36:778, 1964.

9. SIDBURY, Jr., J. B. \& MCCARTY, K. - Further studies on cerebro-oculo-renal syndrome. South. Med. J. (Alabama) 56:1441, 1963.

\section{Moléstia de Gaucher}

1. BARLOW, C. F. - Neuropathologic findings in a case of infantile Gaucher's disease. J. Neuropath. Exper. Neurol. 16:238, 1957.

2. EPSTEIN, E. - Zur Chemie der Gaucherschen Krankheit und Frage der sogenanntenn Lipoidzellen hyperplasie. Klin. Wchnschr 3:21, 1924.

3. FRENCH, J. H.; BROTZ, M. \& POSER, C. M. - Lipid concentration of the brain in infantile Gaucher's disease. Neurology 19:81, 1969.

4. LIEB, H. - Cerebrosidseicherung bei Splenomegalie Typ Gaucher. Z. physiol. Chem. 140:305, 1924.

5. LINDAU, A. - Un cas de maladie de Gaucher. Acta path. microbiol. scand. $5: 22,1928$.

6. MALONEY, A. F. J. \& CUMINGS, J. N. - A case of juvenile Gaucher's disease with intraneuronal lipid storage. J. Neurol. Neurosurg. Psychiat. 23:207, 1960.

7. OBERLING, C. \& WORINGER, P. - La maladie de Gaucher chez le nourisson. Rev. franc. Pédiat. 3:475, 1927.

8. PHILIPPART, M.; ROSENSTEIN, B. \& MENKES, J. H. - Isolation and characterization of the main splenic glycolipids in the normal organ and in Gaucher's disease. J. Neuropath. Exper. Neurol. 24:290, 1965.

9. SCARAVILLI, F. \& TAVOLATO, B. - Neuropathological aspects of the infantile form of Gaucher's disease. Acta neurol. belg. 68:674, 1968.

10. SCHAIRER, E. - Die Gehirnveränderungen beim Morbus Gaucher des Sauglings. Virchows Arch. 315:395, 1948.

11. THANNHAUSER, S. J. - Lipidoses of Cellular Lipid Metabolism. Oxford Press, New York, 1950.

12. TANNHAUSER, S. J. - Diseases of the nervous system associated with disturbances of lipid metabolism. Res. Nerv. Ment. Dis. Proc. 32:238, 1953.

\section{Idiotias amauróticas}

1. ANDERSON, E.; CORONINI, C.; STURM, A. \& KOVAC-WIEN, W. - A comparison of the histochemistry of the cerebral cortex from siblings with gargoylism and Tay-Sachs' disease. Acta Neurovegetativa 25:3, 20-309, 1963.

2. ARONSON, S. M.; SAIFER, A. \& VOLK, B. W. - Pathophysiologic evolution of amaurotic familial idiocy. Arch. Psychiat. 80:457, 1958.

3. BATZDORF, U.; SARLIEVE, L. L.; GOLD, V. \& MENKES, J. H. - Tay-Sachs disease: demonstration of the stored ganglioside in cultured cells from brain biopsy. Arch. Neurol. 20:650, 1969.

4. CRAWLEY, J. W. - Three cases of juvenile form of amaurotic family idiocy (Vogt-Spielmeyer disease) with EEG findings. J. Pediat. 51:571, 1957.

5. FOG, T. \& MUNKVAD, I. - So-called lipidoses: their histopathology and chemistry with special reference to a case of amaurotic idiocy. Acta psychiat. neurol. 30:197, 1955.

6. JAMPEL, R. \& QUAGLIO, N. D. - Eye movements in Tay-Sachs disease. Neurology (Minneapolis) $14: 1013,1964$.

7. JULIAO, O. F.; CANELAS, H. M. \& LONGO, N. A. - Idiotia amaurótica familiar, forma juvenil. Arq. Neuro-Psiquiat. (São Paulo) 14:136, 1956.

8. KÄFER, J. P.; POCH, G. F.; HERSKOVITS, E.; VIGNAU, P. A. \& UDABE, R. U. - Idiocia amaurótica tardia e enfermedad de Kufs (quatro nuevos casos). Rev. Neurol. Buenos Aires 21, 4:120, 1963. 
9. KLENK, E. - Beitrage zur Chemie der Lipoidosen, Niemann-Picksche Krankheit und amaurotische Idiote. Ztsch. f. physiol. Chem. 262:128, 1939-40.

10. NORMAN, R. M. \& WOOD, N. - Une forme congénitale d'idiotie familiale amaurotique. J. Neurol. Psychiat. 4:175, 1941.

11. SHANKLIN, W. M.; ISSIDORIDES, M. \& SALAM, M. - Histochemistry of the cerebral cortex from a case of amaurotic family idiocy. J. Neuropath. Exper. Neurol. 21:2, 1962.

12. SJöGREN, T. - Die Juvenile amaurotische Idiotie. Klinische und erblichkeitsmedizinische Untersuchungen. Hereditas 14:197, 1931.

13. THIEFFRY, S.; BERTRAND, I.; BARGETON, E.; EDGAR, G. W. F. \& ARTHUIS, M. - Idiotie amaurotlque infantile avec altérations graves de la substance blanche. Rev. Neurol. 102, 2:130, 1960.

14. TOURTEllotTe, W. W.; AlleN, R. J.; HAERER, A. F. \& BRYAN, E. R. Study of lipids in cerebrospinal fluid and serum in Tay-Sachs disease. Arch. Neurol. (Chicago) 12:300, 1965.

15. Van BOGAERT, L. \& KLEIN, D. - Observations sur l'hérédité des idioties amaurotiques et de la spléno-hépatomégalie lipidienne. J. Génét. Hum. 4:23, 1955.

16. ZEMAN, W. \& HOFFMAN, J. - Juvenile and late forms of amaurotic idiocy in one family. J. Neurol. Neurosurg. Psychiat. 25:352, 1962.

\section{Moléstia de Niemann-Pick}

1. BURNE, J. C. - Niemann-Pick disease in foetus. J. Path. \& Bact. 66:473, 1953.

2. CROCKER, A. C. - The cerebral defect in Tay-Sachs disease and NiemannPick disease. J. Neurochem. 7:69, 1961.

3. CROCKER, A. C. \& FERBER, S. - Niemann-Pick disease: a review of 18 patients. Medicine 37:1, 1958.

4. FREDERICKSON, D. S. - Sphingomyelin Lipidosis: Niemann-Pick Disease. In J. Stanbury, J. Wyngaarden and D. S. Frederickson, editors - The Metabolic Basis in Inherited Disease, ed. 2.a, McGraw-Hill Book Co., New York, 1966.

5. IVEMARK, B. I. et al. - Niemann-Pick disease in infancy: report of two siblings with elinical, histologic and chemical studies. Acta Paedlat. 52:391, 1963.

6. KLENK, E. - Sur les acides gras non saturés des phosphatides du cerveau solubles dans l'éther. Zschr physiol. Chem. 206:25, 1932.

7. KLENK, E. - Zur la nature des phosphatides et des autres lipides dans le cerveau et le foie. Zschr. physiol. Chem. 235:24, 1935.

\section{Leucodistrofias}

1. ALLEN, R. J.; McCUSKER, J. J. \& TOURTELLOTTE; W. E. - Metachromatic leucodystrophy: clinical, histochemical and cerebrospinal fluid abnormalities. Pediatrics 30:629, 1962.

2. AUSTIN, J. H. - Metachromatic form of diffuse cerebral sclerosis: diagnosis during life by urine sediment examination. Neurology 7:415, 1957.

3. AUSTIN, J. H. - Metachromatic form of diffuse cerebral sclerosis: diagnosis during life by isolation of metachromatic lipids from urine. Neurology 7:716, 1957.

4. AUSTIN, J. H. - Metachromatic form of diffuse cerebral sclerosis: significance of sulfatide and other lipid abnormalities in white matter and kidney. Neurology $10: 470,1960$. 
5. BERTRAND, I.; THIEFFRY, S. \& BARGETON, E. - Leucodystrophia familiale et détermination splénohépatique caractérisant un trouble général du métabolisme. Rev. Neurol. 91:161, 1954.

6. BLACKWOOD, W. \& CUMINGS, J. N. - A histological and chemical study of three cases of diffuse cerebral sclerosis. J. Neurol. Neurosurg. Psychiat. $17: 33,1954$.

7. BRANTE, G. - Studies on lipids in the nervous system with special reference to quantitative chemical determination and tropical distribution. Acta physiol. scand. 18, supl. 163, 1949.

8. CANElAS, H. M.; IRIYA, K.; ESCALANTE, O. D. \& DE JORGE, F. B. Leucodistrofia metacromática. Estudo clínico-laboratorial de cinco casos na mesma familia. Rev. paul. Med. 63:355, 1963.

9. CHRISTENSEN, E.; MELCHIOR, J. \& NEGRI, S. - A comparative study of 16 cases of diffuse sclerosis with special reference to the histopathological findings. Acta neurol. scand. 37:163, 1961.

10. COLLIER, J. \& GREENFIELD, J. G. - The encephalitis periaxialis of Schilder: a clinical and pathological study, with an account of two cases, one of which was diagnosed during life. Brain 47:489, 1924.

11. CUMINGS, J. M. - Lipid chemistry of the brain in demyelinating diseases. Brain 78:554, 1955.

12. CUMINGS, J. N. - Abnormalities of lipid chemistry in cerebral lipidoses and demyelinating conditions. In J. N. Cumings: Modern Scientific Aspects of Neurology. E. Arnold, London, 1960.

13. DIEZEL, P. B. - Lipidosis of the Central Nervous System. In Cumings J. N.: Modern Scientific Aspects of Neurology. E. Arnold, London, pág. 98.

14. EDGAR, G. W. F. - Approche biochimique des lipidoses et des leucodystrophies. Rev. Neurol. 92:277, 1955.

15. EDGAR, G. W. F. - The investigation of demyelinating diseases and quantitative determination of "myelin lipids". Mschr. Psychiat. Neurol. 131:274, 1956.

16. EDGAR, G. W. F. - Neurochemical aspects of leucodystrophy. Psychiat. Neurol. Neurochir. 64:28, 1961.

17. FERRARO, A. - Familial form of encephalitis periaxialis diffusa. J. nerv. ment. Dis. 66:329, 479:616, 1927.

18. HAGBERG, B. - Clinical symptoms, signs and tests in metachromatic leucodystrophy. In J. Folch-Pi \& HJ Bauer: Brain Lipids and Lipoproteins and the Leucodystrophies. Elsevier, Amsterdam, 1963.

19. HAGBERG, B. \& SVENNERHOLM, L. - Metachromatic leucodystrophy - a generalized lipidosis. Determination of sulfatide in urine, blood plasma and cerebrospinal fluid. Acta paediat. (Uppsala) 48:690, 1960.

20. HANSEN, E.; OLSEN, S. \& PLUM, C. M. - Hereditary progressive cerebral leucodystrophy. Acta neurol. scand. 37:208, 1961.

21. JATZKEWITZ, H. - Zwei Typen von Cerebrosid-Schwefolsäyreestern als sog. Praelipoide und Speichersubstanzen bei der Leukodystrophie Typ Scholz (metachromatische Form der diffusen Sklerose). Z. Physiol. Chem. 311:279, 1958.

22. JERVIS, G. A. - Infantile metachromatic leukodystrophy (Greenfield's disease). J. Neuropath. 19:323, 1960.

23. NORMAN, R. M. - Diffuse progressive metachromatic leucoencephalopathy: a form of Schilder's disease related to the lipidoses. Brain 70:234, 1947.

24. NORMAN, R. M. - Lipid diseases of the brain. In D. Williams: Modern Trends in Neurology. Butterworths, London, 1962.

25. NORMAN, R. N.; URICH, H. \& TINGEY, A. H. - Metachromatic leuco-encephalopathy: a form of lipidosis. Brain 83:369, 1960.

26. PFEIFFER, J. - Differentiation of various types of leucodystrophy. WId. Neurol. 3:580, 1962.

27. SEITELBERGER, F. - Histochemistry of demyelinating disease proper, including allergic encephalomyelitis and Pelizaeus-Merzbacher's disease. In J. N. Cumings: Modern Scientific Aspects of Neurology, E. Arnold, London, 1960. 
28. SVENNHERHOLM, L. - Some aspects of the biochemical changes in leudodystrogy. In J. Folch-Pi \& H. J. Bauer: Brain Lipids and Lipoproteins and the Leucodystrophies. Elsevier, Amsterdam, 1963.

29. van BOGAERT, L. \& NYSSEN, R. - Le type tardif de la leucodystrophie progressive familiale, Rev. Neurol. 65:21, 1936.

30. von HIRSCH, T. \& PEIFFER, J. - Uber histologische Methoden in der Differentialdiagnose von Leukodystrophien und Lipoidosen. Arch. Psychiat. Nervenhk. 194:88, 1955.

\section{Moléstia de Refsum}

1. ALEXANDER, W. S. - Phytanic acid in Refsum's syndrome. J. Neurol. Neurosurg. Psychiat. 29:412, 1966.

2. ASHENHURST, E. M.; MILlAR, B. H. D. \& MILlIKEN, T. G. - Refsum's syndrome affecting a brother and two sisters. Brit. med. J. 2:415, 1958.

3. BONDUElle, M.; BOUYGUES, P.; LORMEAU, G. \& DELOUX, G. - Maladie de Refsum: Etude des lipides du sérum et des urines. Rev. Neurol. 115, 5:933, 1966.

4. ELDJARN, L. - Heredopathia atactica polyneuritiformis (Refsum's disease): a defect in the omega-oxidation mechanism of fatty acids. Scand. J. clin. Lab. Invest. 17:178, 1965.

5. KJELlSON, L. - Refsum's sjukdom (Refsum syndrome). Nord. Med. 49:460, 1953.

6. KLENK, E. \& KAHLKE, W. - Uber das Vorkommen der 3, 7, 11, 15-tetramethylhexadensäure (Phytansäure) im den Cholesterinestern und anderen lipoidfraktionen der Organe bei einem Krankheitsfall unbekannter Genese (verdacht auf Heredopathia atactica polyneuritiformis - Refsum syndrom). Hoppe-Seylers Z. physiol. Chem. 333:133, 1963.

7. REESE, H. \& BARETA, J. - Heredopathia atactica polyneuritiformis. J. Neuropath. Exper. Neurol. 9:385, 1950.

8. REFSUM, S. - Heredopathia atactica polyneuritiformis; a familial syndrome not hitherto described. Acta psychiat. scand. supl. 38, 1946.

9. REFSUM, S.; SALOMONSEN, L. \& SKATVEDT, M. - Heredopathia atactica polyneuritiformis in children. J. Pediat. 35:335, 1949.

10. RICHTERICH, R.; ROSIN, S. \& ROSSI, E. - Refsum's disease (heredopathia atactica polyneuritiformis). An inborn error of lipid metabolism with storage of $3,7,11,15$-tetramethylhexadecanoic acid. Formal genetics. Humangenetik 1:333, 1965.

11. SPINA-FRANCA, A.; ANGHINAH, A. \& MATTOSINHO-FRANÇA, L. C. Heredopatia atáctica polineuritiforme. Arq. Neuro-Psiquiat. (São Paulo) 26: $165,1968$.

12. STEINBERG, D.; AVIGAN, J.; MIZE, C. \& BAXTER, J. - Phytanic acid formation and accumulation in phytol ped rats. Biochem. Biophys. Res. Commun. 19:412, 1965.

13. STEINBERG, D.; VROOM, F. Q.; ENGEL, W. K.; CAMMERMEYER, J.; MIZE, C. E. \& AVIGAN, J. - Refsum's disease; a recently characterized lipidosis involving the nervous system. Ann. Int. Med. 66:365, 1967.

14. STOFFEL, W. \& KAHLKE, W. - The transformation of phytol into phytanic acid in heredopathia atactica polyneuritiformis (Refsum's syndrome). Biochem. Biophys. Res. Commun. 19:412, 1965.

15. ThIEBAUT, F.; Lemoyne, J. \& GUillaumat, L. - Maladie de Refsum. Rev. Neurol. (Paris) 104:152, 1961.

16. TOUSSAINT, D.; COERS, C. \& TOPPET, N. - Heredopathia atactica polyneuritiformis (syndrome de Refsum): constatations cliniques et biopsiques. Bull. Soc. Belg. Ophtal. 122:383, 1959. 


\section{Syndrome de Bassen-Kornzweig}

1. BASSEN, F. A. \& KORNZWEIG, A. L. - Malformation of the erythrocytes in a case of atypical retinitis pigmentosa. Blood 5:381, 1950.

2. DRUEZ, G.; LAMY, M.; FREZAL, J.; POLONOVSKI, J. \& REY, J. - L'acanthocytose: ses rapports avec l'absence congénitale de B-lipoproteines. Presse Méd. 69:1546, 1961.

3. JAMPEL, R. S. \& FALLS, H. F. - Atypical retinitis pigmentosa, acanthrocytosis and heredodegenerative neuromuscular disease. Arch. Ophthal. (Chicago) $59: 818,1958$.

4. KORNZWEIG, A. L. \& BASSEN, F. A. - Retinitis pigmentosa, acanthrocytosis and heredodegenerative neuromuscular disease. Arch. Ophthal. (Chicago) 58·183. 1957.

5. MABRY, C. C.; DIGEORGE, A. M. \& AUERBACH, V. H. - Studies concerning tne defect in a patient with acanthrocytosis. Clin. Res. 8:371, 1960.

6. SALT, H. B.; WOLFF, O. H.; LOYD, J. K.; FOSBROOKE, A. S. \& HUBBLE, D. $\mathrm{X}$. - On having no B-lipoprotein: a syndrome comprising A-B-lipoproteinaemia, acanthocytosis and steatorrhoea. Lancet $2: 325,1960$.

7. SCHARTZ, J. F.; ROWLAND, L. P.; EDER, H.; MARKS, P. A.; OSSERMAN, E. F.; HIRSCHBERG, E. \& ANDERSON, H. - Basen-Kornzweig syndrome: deficiency of servum B-lipoprotein. Arch. Neurol. (Chicago) 8:438, 1963.

8. WOLFF, J. A. \& BAUMAN, W. A. - Studies concerning acanthrocytosis: a new genetic syndrome with absent B-lipoprotein. Amer. J. Dis. Child. 102:478, 1961.

\section{Galactosemia}

1. LAMY, M.; ROYER, P. \& FREZAL, J. - Maladies Héréditaires du Metabolisme chez l'Enfant. Masson, Paris, 1959.

2. NORDMANN, J. \& MANOEL, P. - Un aspect biochimique du cristallin du rat an cours d'un régime riche en galactose et dans le diabéte alloxanique. $C$. r. Acad. Sci. (Paris) 236, 1953.

3. RAMOS, J. L. A. \& NOBREGA, F. J. - Prevenção da deficiência mental conseqüente a defeitos hereditários do metabolismo. Rev. paul. Med. 66:96, 1965.

4. STANBURY, J. B.; WYNGAARDEN, J. B. \& FREDRICKSON, D. S. - The Metabolic Basis of Inherited Disease. McGraw-Hill, New York, 1960.

\section{Moléstia de Pompe}

1. CROME, J.; CUMINGS, J. N. \& DUCKETT, S. - Neuropathological and neurochemical aspects of generalized glycogen storage disease. J. Neurol. Neurosurg. Psychiat. 26:422, 1963.

2. ESSER, M. \& SCHEIDEGGER, S. - Glykogenkrankheir. Schweiz Med. Wochen. $67: 970,1937$.

3. FIELD, R. A. - Glycogen Deposition Diseases. In The Metabolic Basis of Inherited Disease: Stanbury J. B.; Wyngaarden J. B. \& Fredrickson D. S., editors. McGraw-Hill Book Co., New York, 1960.

4. GITZELMANN, R. - Glykogenprobleme bei den Glykogenspeicherungskrankheiten. Helv. Paed. Acta 12:425, 1957.

5. HERS, H. G. - Alpha-glucosidase deficiency in generalized glycogen storage disease (Pompe's disease). Biochem. J. 86:11, 1963.

6. HUIFING, F.; van CREVELD, S. \& LOSEKOOT, G. - Diagnosis of generalized glycogen storage disease (Pompe's Disease). J. Pediat. 63:984, 1963.

7. KIMMELSTEIL, P. - Über Glykogenose. Beit. z. path. Anat. u. z. allgem. Path. 91:1, 1933. 
8. MANCALL, E. L.; APONTE, G. E. \& BERRY, R. G. - Pompe's disease (diffuse glucogenosis) with neuronal storage. J. Neuropathol. Exper. Neurol. 24, 1:85, 1965.

9. POMPE, J. C. - Over idiopatische Hypertrophie van Het Hart. Nederl Tidschr v. Geneesk 76:304, 1932.

10. SCHNABEL, R. - Uber die neuromuskuläre Form der Glykogenspeicherungskrankheit. Virch. Arch. f. Path. Anat, u. Physiol. u. f. Klin. Med. 331:287, 1958.

11. UNSHELM, E. - Die Glykogenkrankheit (Zugleich ein Beitrag zur Frage des Hepatogenen Infantilismus). Jahrb. f. Kinderheilk. 137:257, 1932.

\section{Moléstia de Mc Ardle}

1. DYKEN, M. L.; SMITH, D. M. \& PEAKE, R. L. - An electromyographic diagnostic. screening test in Mc Ardle's disease: a case report. Neurology (Minneapolis) $17: 45,1967$.

2. Mc ARDLE, B, - Myopathy due to a defect in muscle glycogen breakdown. Clin. Sci. 10:13, 1951.

3. PEARSON, C. M.; RIMER, D. \& MOMMAERTS, W. F. H. M. - A metabolic myopathy due to absence of muscle phosphorylase. Amer. J. Med. 30:502, 1961.

4. ROWLAND, L. P.; ARAKI, S. \& CARMEL, P. - Contracture in Mc Ardle's disease. Arch. Neurol. (Chicago) 13, 5:541, 1965.

5. ROWLAND, L. P.; LOVELACE, R. E.; SCHOTLAND, D. L.; ARAKI, S. \& CARMEL, P. - The clinical diagnosis of Mc Ardle's disease: identification of another family with deficiency of muscle phosphorylase. Neurology (Minneapolis) 16:93, 1966.

6. SALTER, R. H.; ADAMSON, D. G. \& PEARCE, G. W. - Mc Ardle's syndrome (myophosphorylase deficiency): a study of a family. Quart. J. Med, 36:565, 1967.

7. SCHMID, R. \& HAMMAKER, L. - Hereditary absence of muscle phosphorylase (Mac Ardle's syndrome). New Engl. J. Med. 264:223, 1961.

8. SCHOTLAND, D. L.; SPIRO, D.; ROWLAND, L. P. \& CARMEL, P. - Uitrastructural studies of muscle in Mc Ardle's disease (deficiency of muscle phosphorylase). J, Neuropathol. Exper. Neurcl. 24, 4:629, 1965.

\section{Moléstìa de Tarui}

1. TARUI, S.; OKUNO, G.; IKURA, Y.; TANAKA, T.; SUTA, M. \& NISHIKAWA, M. - Phosphofructokinase deficiency in skeletal muscles; a new type of glycocogenosis. Biochem. biophys. Res. Commun. 19:517, 1965.

\section{Molèstia de Thomson}

1. THOMSON, W. H. S.; MacLAURIN, J. C. \& PRINEAS, J. W. - Skeletal muscle glycogenosis; an investigation of two dissimilar cases. J. Neurol. Neurosurg. Psychiat. 26:60, 1963.

\section{Intolerância hereditária à frutose}

1. CHAMBERS, R. A. \& PRATT, R. T. C. - Idiosyncrasy to fructose Lancet $2: 346,1956$. 
2. DUBOIS, R.; LOEB, H.; OOMS, H. A.; GILlET, P.; BARTHMAN, J. \& CHAMPENOIS, A. - Etude d'un cas d'hypoglycémie fonctionelle par intolérance au fructose. Helv. Paediat. 16:90, 1961.

3. FREZAL, J. \& REX, J. - La galactosemie et l'intolerance héréditaire au fructose. Méd. Infant. 5:303, 1962.

4. FROESCH, E. R. - Essential fructosemia and hereditary fructose intolerance. In The Metabolic Basis of Inherited Diseases, edit. por J. B. Stanbury, J. B. Wyngaarden \& D. S. Frederickson. McGraw-Hill, New York, 1966.

\section{Gargulismo}

1. BISHTON, R. L.; NORMAN, R. M. \& TINGEY, A. - The pathology and chemistry of a case of gargoylism. J. Clin. Pathol. 9:305, 1956.

2. DAWSON, I. M. P. - The histology and histochemistry of gargoylism. J. Pathol. a. Bacteriol. 67:587, 1954.

3. DIEZEL, P. B. - Lipidoses of the Central Nervous System. In Modern Scientific Aspects of Neurology. Edit. por J. N. Cummings. Edward Arnold, London, 1960.

4. JERVIS, G. A. - Familial mental deficiency akin to amaurotic idiocy and gargoylism. Arch. Neurol. a. Psychiat. 47:943, 1942.

5. JERVIS, G. A. - Gargoylism (lipochondrodystrophy): a study of ten cases with emphasis on the formes frustes of the disease. Arch. Neurol. Psychiat. 63:681, 1950.

6. LEFEVRE, A. B.; SOUSA E SILVA, O. R.; MARQUES, J. C. \& AGUIAR, L. B. - Sindrome de Hunter-Hurler. Arq. Neuro-Psiquiat. (Sāo Paulo) 12:41, 1954.

7. SENA, P. G. \& CAYMMI, M. - Sôbre um caso de gargulismo com estudo anátomo-patológico. Arq. Neuro-Psiquiat. (São Paulo) 20:40, 1962.

\section{Degeneracão hepatolenticular}

1. BEARN, A. G, - Genetic and biochemical aspects of Wilson's disease. Amer. J. Med. 15:442, 1953.

2. BICKEL, H. - Attemps at ceruloplasmin substitution in Wilson's disease. In Wilson's Disease: Some Current Concepts. Edit. por J. M. Walsche e J. N. Cummings. Blackwell, Oxford, 1961.

3. CANELAS, H. M.; DE JORGE, F. B. \& TOGNOLA, W. A. - Metabolic balances. of copper in patients with hepatolenticular degeneration submitted to vegetarian and mixed diets. J. Neurol. Neurosurg. Psychiat. 30:371, 1967.

4. CANELAS, H. M.; DE JORGE, F. B. \& TOGNOLA, W. A. - Metabolic balances of sulfur in patients with hepatolenticular degeneration and effect of the use of D-penicillamin. Arq. Neuro-Psiquiat. (São Paulo) 27:267, 1969.

5. CANELAS, H. M.; ESCALANTE, O. D.; DE JORGE, F. B. \& ROCHA-QUINTAO, E. C. - Hepatolenticular degeneration: clinical and biochemical study of three cases. Arq. Neuro-Psiquiat. (São Paulo) 21, 4:229, 1963.

6. CARTWRIGHT, G. E. \& WINTROBE, M. M. - The question of copper deficiency in man. Amer. J. Clin. Nutrit. 15:94, 1964.

7. GERMAN, J. L. \& BEARN, A. G. - Effects of estrogens on copper metabolism in Wilson's disease. J. Clin. Invest. 40:445, 1961.

8. GOLDSTEIN, N. P.; RANDALL, R. V.; GROSS, J. B. \& McGUCKIN, W. F. Copper balance in Wilson's disease. Arch Neurol. (Chicago) 12:456, 1965.

9. HALL, H. C. - La Dégénérescence Hépato-lenticulaire: Maladie de WilsonPseudosclérose. Masson, Paris, 1921.

10. HALL, G. \& NEALE, F. C. - Wilson's disease. Lancet 1:1089, 1957.

11. HERMANN, G. E. \& KUN, E. - Intracellular distribuction of copper in rat liver and its response to hypophysectomy and growth hormone. Exper. Cel. Res. $22: 257,1961$. 
12. HILL, L. \& WALSHE, J. M. - The action of chelating agents im Wilson's disease. Lancet 2:444, 1969.

13. MORELL, A. G.; SHAPIRO, J. R. \& SCHEINBERG, I. H. - Copper binding protein from human liver. In Wilson's Disease; Some Current Concepts. Editado por J. M. Walshe e J. N. Cummings. Blackwell, Oxford, 1961.

14. O'REILLY, S. - Observations on ceruloplasmin and methods for its stimation. Neurology (Minneapolis) 11:259, 1961.

15. O'REILLY, S. - Problems in Wilson's disease. Neurology (Minneapolis) 17:137, 1967.

16. PORTER, H. - Tissue copper proteins in Wilson's disease. Arch. Neurol. (Chicago) 11:341, 1964.

17. SCHEINBERG, I. H. \& GITLIN, D. - Deficiency of ceruloplasmin in patients with hepatolenticular degeneration (Wilson's disease). Science 116:484, 1952.

18. SUNDERMAN, F. W. Jr.; WHITE, J. C. \& SUNDERMAN, F. W. - Metabolic balance studies in hepatolenticular degeneration treated with diethyldithiocarbamate. Amer. J. Med. 34:875, 1963.

19. UZMAN, L. L. - Experience with tissue copper in Wilson's disease and results of treatment. In Metal Binding in Medicine. Editado por Seven e Johnson. Lippincott, New York, 269, 1960.

20. UZMAN, L. L.; IBER, F. L.; CHALMERS, T. C. \& KNOWLTON, M. - Mechanism of copper deposition in the liver in hepatolenticular degeneration (Wilson's disease). Amer. J. med. Sci. 231:511, 1956. 